\title{
Kinetics of Inhibitory Feedback from Horizontal Cells to Photoreceptors: Implications for an Ephaptic Mechanism
}

\author{
Ted J. Warren, ${ }^{1,2 *}$ @Matthew J. Van Hook, ${ }^{1 *}$ ๑Daniel Tranchina, ${ }^{3}$ and $\odot$ Wallace B. Thoreson ${ }^{1,2}$ \\ ${ }^{1}$ Truhlsen Eye Institute and Department of Ophthalmology \& Visual Sciences, University of Nebraska Medical Center, Omaha, Nebraska 68198, \\ ${ }^{2}$ Department of Pharmacology \& Experimental Neuroscience, University of Nebraska Medical Center, Omaha, Nebraska 68198, and ${ }^{3}$ Department of Biology \\ and Courant Institute of Mathematical Sciences, New York University, New York, New York 10003
}

Inhibitory feedback from horizontal cells (HCs) to cones generates center-surround receptive fields and color opponency in the retina. Mechanisms of HC feedback remain unsettled, but one hypothesis proposes that an ephaptic mechanism may alter the extracellular electrical field surrounding photoreceptor synaptic terminals, thereby altering $\mathrm{Ca}^{2+}$ channel activity and photoreceptor output. An ephaptic voltage change produced by current flowing through open channels in the HC membrane should occur with no delay. To test for this mechanism, we measured kinetics of inhibitory feedback currents in Ambystoma tigrinum cones and rods evoked by hyperpolarizing steps applied to synaptically coupled HCs. Hyperpolarizing HCs stimulated inward feedback currents in cones that averaged $8-9 \mathrm{pA}$ and exhibited a biexponential time course with time constants averaging 14-17 ms and 120-220 ms. Measurement of feedback-current kinetics was limited by three factors: (1) HC voltage-clamp speed, (2) cone voltage-clamp speed, and (3) kinetics of $\mathrm{Ca}^{2+}$ channel activation or deactivation in the photoreceptor terminal. These factors totaled $\sim 4-5 \mathrm{~ms}$ in cones meaning that the true fast time constants for HC-to-cone feedback currents were $9-13 \mathrm{~ms}$, slower than expected for ephaptic voltage changes. We also compared speed of feedback to feedforward glutamate release measured at the same cone/HC synapses and found a latency for feedback of 11-14 ms. Inhibitory feedback from HCs to rods was also significantly slower than either measurement kinetics or feedforward release. The finding that inhibitory feedback from HCs to photoreceptors involves a significant delay indicates that it is not due to previously proposed ephaptic mechanisms.

Key words: ephapse; horizontal cell; L-type calcium current; lateral inhibition; photoreceptor; retina

Significance Statement

Lateral inhibitory feedback from horizontal cells (HCs) to photoreceptors creates center-surround receptive fields and coloropponent interactions. Although underlying mechanisms remain unsettled, a longstanding hypothesis proposes that feedback is due to ephaptic voltage changes that regulate photoreceptor synaptic output by altering $\mathrm{Ca}^{2+}$ channel activity. Ephaptic processes should occur with no delay. We measured kinetics of inhibitory feedback currents evoked in photoreceptors with voltage steps applied to synaptically coupled HCs and found that feedback is too slow to be explained by ephaptic voltage changes generated by current flowing through continuously open channels in $\mathrm{HC}$ membranes. By eliminating the proposed ephaptic mechanism for $\mathrm{HC}$ feedback regulation of photoreceptor $\mathrm{Ca}^{2+}$ channels, our data support earlier proposals that synaptic cleft $\mathrm{pH}$ changes are more likely responsible.

\section{Introduction}

Synaptic processing of visual information begins at photoreceptor synapses. Similar to lateral inhibition discovered in Limulus

Received April 1, 2016; revised Aug. 10, 2016; accepted Aug. 12, 2016.

Author contributions: T.J.W., M.J.V.H., and W.B.T. designed research; T.J.W., M.J.V.H., and W.B.T. performed research; D.T. contributed unpublished reagents/analytic tools; T.J.W., M.J.V.H., D.T., and W.B.T. analyzed data; T.J.W., M.J.V.H., D.T., and W.B.T. wrote the paper.

This work was supported by National Institutes of Health Grants R01EY10542 to W.B.T. and F32EY023864 to M.J.V.H., and Research to Prevent Blindness Senior Scientific Investigator Award to W.B.T. We thank Dr. Scott Nawy (University of Nebraska Medical Center) for helpful suggestions; and Kevin Blum and Benjamin Fogelson (New York University's Courant Institute of Mathematical Sciences) for related discussions of their recent spatiotemporal mathematical modeling of ephaptic feedback from HCs to cones. retina (Hartline et al., 1956), inhibitory feedback from retinal horizontal cells (HCs) to cones and rods in vertebrate retina generates center-surround receptive fields important for spatiotemporal gain control (Cadenas et al., 1994; Reifsnider and Tranchina, 1995; VanLeeuwen et al., 2009), edge detection and

The authors declare no competing financial interests.

*T.J.W. and M.J.V.H. contributed equally to this work.

Correspondence should be addressed to Dr. Wallace B. Thoreson, Department of Ophthalmology \& Visual Sciences, 4050 Durham Research Center I, University of Nebraska Medical Center, Omaha, NE 68198-5840. E-mail: wbthores@unmc.edu.

DOI:10.1523/JNEUROSCI.1090-16.2016

Copyright $\odot 2016$ the authors $\quad 0270-6474 / 16 / 3610075-14 \$ 15.00 / 0$ 
color-opponent interactions important for color vision (for review, see Thoreson and Mangel, 2012). Despite years of study since horizontal cell feedback was first found in vertebrate retina (Baylor et al., 1971), its mechanisms remain unsettled (Thoreson and Mangel, 2012; Kramer and Davenport, 2015). It was initially proposed that HC feedback might involve GABAergic disinhibition (Lam et al., 1978). While GABA plays a role (Wu, 1991; Tatsukawa et al., 2005; Liu et al., 2013; Kemmler et al., 2014; Hirano et al., 2016), the inability of GABA receptor antagonists to block feedback in a variety of species showed the importance of other mechanisms (Thoreson and Burkhardt, 1990; Verweij et al., 1996, 2003; Hirasawa and Kaneko, 2003). In particular, it has been found that HCs inhibit synaptic release from photoreceptors by shifting the voltage dependence of L-type $\mathrm{Ca}^{2+}$ channels in cone and rod terminals (Verweij et al., 1996; Thoreson et al., 2008). Two mechanisms have been proposed to account for feedback regulation of photoreceptor $\mathrm{I}_{\mathrm{Ca}}$. One is chemical involving local $\mathrm{pH}$ changes in the synaptic cleft (Hirasawa and Kaneko, 2003; Wang et al., 2014), and the other is a purely electrical ephaptic mechanism (Byzov and Shura-Bura, 1986). For the latter, Byzov and Shura-Bura (1986) proposed that current flowing through the invaginating synaptic cleft into HCs when they hyperpolarized to light could produce small local changes in extracellular voltage sensed by adjacent $\mathrm{Ca}^{2+}$ channels in the cone terminal. Kamermans et al. (2001a) elaborated on this mechanism by hypothesizing that currents responsible for ephaptic voltage changes flowed through continuously open hemigap junctions at tips of $\mathrm{HC}$ dendrites.

The term ephaptic was derived by Arvanitaki (1942) from a Greek word meaning the act of touching. Electrical communication through gap junctions is common (Pereda, 2014), but examples of ephaptic communication are more limited (Anastassiou and Koch, 2015). Ephaptic voltage changes arising from current flow through continuously open channels are effectively instantaneous. The presence of ephaptic transmission can therefore be demonstrated by showing that it is faster than conventional chemical synaptic transmission or that it matches time-resolution capabilities of the electrode (Blot and Barbour, 2014). In goldfish retina, $\mathrm{HC}$ light responses and responses of cones to light-evoked changes in negative feedback from HCs showed nearly identical kinetics, leading to the suggestion that a component of negative feedback from HCs is instantaneous (Kamermans et al., 2001b; Vroman et al., 2013, 2014). However, light response kinetics of photoreceptors and HCs are slow, with times to peak of tens of milliseconds (Baylor et al., 1971; Yamada et al., 1985; Yang and $\mathrm{Wu}, 1989)$. The inherently slow kinetics of HC light responses limits the temporal resolution of comparisons with small, slow cone feedback responses. To rapidly alter HC feedback and test for an ephaptic mechanism, we measured kinetics of inhibitory feedback by applying voltage steps to HCs while recording feedback-induced changes in $\mathrm{Ca}^{2+}$ currents $\left(\mathrm{I}_{\mathrm{Ca}}\right)$ from simultaneously voltage-clamped rods and cones. We compared kinetics of feedback-induced changes in photoreceptor $\mathrm{I}_{\mathrm{Ca}}$ with limits placed on measurement resolution by voltage-clamp speeds of the two cells and $\mathrm{Ca}^{2+}$ channel kinetics. Because ephaptic transmission should be faster than chemical transmission, we also compared feedback kinetics to feedforward kinetics of glutamate release from photoreceptors to HCs measured at the same synapses. These comparisons revealed median delays of 7-10 ms for HC-to-cone feedback and 5-8 ms for HC-to-rod feedback, much slower than predicted for an ephaptic mechanism. Eliminating ephaptic voltage changes leaves $\mathrm{pH}$ changes in the cleft as the best candidate for mediating negative feedback regulation of photoreceptor $\mathrm{I}_{\mathrm{Ca}}$ by HCs.

\section{Materials and Methods}

Preparation. Vertical slices of salamander retina were used to study negative feedback from HCs to cones and rods as described in detail previously (Van Hook and Thoreson, 2013). Aquatic phase tiger salamanders (Ambystoma tigrinum, $18-25 \mathrm{~cm}$ in length, both male and female, Charles D. Sullivan) were housed on a $12 \mathrm{~h}$ light/dark cycle. Experiments were performed in light-adapted retinas and begun $1-2 \mathrm{~h}$ into the dark phase. Animals were killed in an ethical manner in accordance with protocols approved by the Institutional Animal Care and Use Committee at the University of Nebraska Medical Center. Salamanders were anesthetized by immersion in MS222 ( $0.25 \mathrm{~g} / \mathrm{L})$ for $\geq 15 \mathrm{~min}$ and then rapidly decapitated and pithed. The head was hemisected and an eye was enucleated. The front of the eye was removed and the remaining eyecup cut into three or four sections. A piece of eyecup was placed with retinal ganglion cells down on a rectangular piece of nitrocellulose filter paper $(5 \times 10$ $\mathrm{mm}$ ). The retina was isolated by peeling away the retinal pigment epithelium, choroid, and sclera. The filter paper and attached retina was cut into $125-\mu \mathrm{m}$-wide strips using a tissue slicer (Stoelting). Slices were rotated 90 degrees and positioned in a recording chamber where they were superfused at $\sim 1 \mathrm{ml} / \mathrm{min}$ with $\mathrm{pH} 7.4$ bicarbonate-buffered amphibian saline solution (all in mM as follows: $101 \mathrm{NaCl}, 22 \mathrm{NaHCO}_{3}, 2.5 \mathrm{KCl}, 2.0$ $\mathrm{CaCl}_{2}, 0.5 \mathrm{MgCl}_{2}, 11$ glucose). Solutions were bubbled continuously with $95 \% \mathrm{O}_{2} / 5 \% \mathrm{CO}_{2}$. For some experiments, this solution was supplemented with HEPES (1-20 mM). When using HEPES, the solution was bubbled for at least 5 min with $95 \% \mathrm{O}_{2} / 5 \% \mathrm{CO}_{2}$ and then the $\mathrm{pH}$ was adjusted to 7.4 using $\mathrm{NaOH}$. In some experiments, we used picrotoxinin to block GABA receptors. Picrotoxin is an equimolar mixture of picrotin and picrotoxinin; the latter is more selective for $\mathrm{GABA}_{\mathrm{a}}$ and $\mathrm{GABA}_{\mathrm{c}}$ receptors (Curtis and Johnston, 1974; Qian et al., 2005; Wang et al., 2007). In other experiments, $\mathrm{CdCl}_{2}$ was diluted from 1:100 stock solution into the superfusate just before application to the retina. Retinal slices were viewed through a long-working distance, water-immersion objective (Olympus $40 \times, 0.7 \mathrm{NA}$ or Nikon $60 \times, 1.0 \mathrm{NA}$ ) on an upright-fixed stage microscope (Olympus BH2-WI or Nikon E600FN).

Electrophysiology. Patch pipettes for whole-cell patch-clamp recordings were pulled from borosilicate glass $(1.2 \mathrm{~mm}$ outer diameter, 0.95 $\mathrm{mm}$ inner diameter, with an internal filament, World Precision Instruments) using a PP-830 micropipette puller (Narishige). The intracellular recording solution used in the patch pipettes consisted of the following (in $\mathrm{mm}$ ): 50 Cs-gluconate, 40 Cs-glutamate, $10 \mathrm{TEA}-\mathrm{Cl}, 3.5 \mathrm{NaCl}, 1$ $\mathrm{CaCl}_{2}, 1 \mathrm{MgCl}_{2}, 9.4 \mathrm{Mg}$-ATP, 0.5 Na-GTP, 5.0 EGTA, 10 HEPES, pH 7.2. Pipette resistance with this solution was between 10 and $15 \mathrm{M} \Omega$. Photoreceptors and HCs were voltage-clamped using a Multiclamp 700A (Molecular Devices) or with an Axopatch 200B patch-clamp amplifier (Molecular Devices) paired with an Alembic VE-2 amplifier (Alembic Instruments). In some experiments, pipette series resistance $\left(\mathrm{R}_{\mathrm{s}}\right)$ was compensated by $70 \%$ using the Multiclamp amplifier circuitry. Wholecell currents were digitized with Axon Digidata 1440A or 1550 interfaces and acquired using Clampex 10 software (Molecular Devices). Voltage values were not corrected for a measured liquid-junction potential (LJP) of $-9 \mathrm{mV}$.

Rods, cones, and HCs were identified by their characteristic anatomical and physiological properties (Van Hook and Thoreson, 2013). To determine whether a photoreceptor and HC were synaptically connected, we tested for an excitatory postsynaptic current (PSC) in the horizontal cell $\left(\mathrm{V}_{\text {hold }}=-60 \mathrm{mV}\right)$ evoked by a step depolarization applied to the photoreceptor $(50-100 \mathrm{~ms}$, from -70 to $-10 \mathrm{mV})$.

Data were analyzed using Clampfit (Molecular Devices) and Prism 4 (GraphPad). Statistical significance was evaluated by regression analysis, Student's $t$ tests, and ANOVA with $p<0.05$. We used MATLAB (The MathWorks, RRID:SCR_001622) to evaluate solutions to our mathematical model for signal propagation in the $\mathrm{HC}$ dendrite in response to a voltage-clamp step applied to the HC soma. 
A

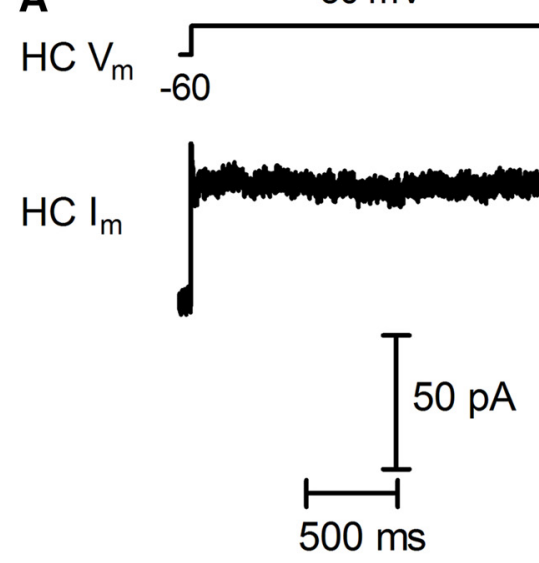

C Feedback current

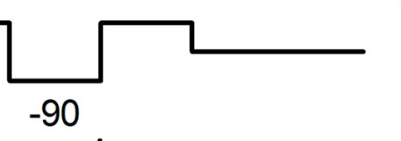

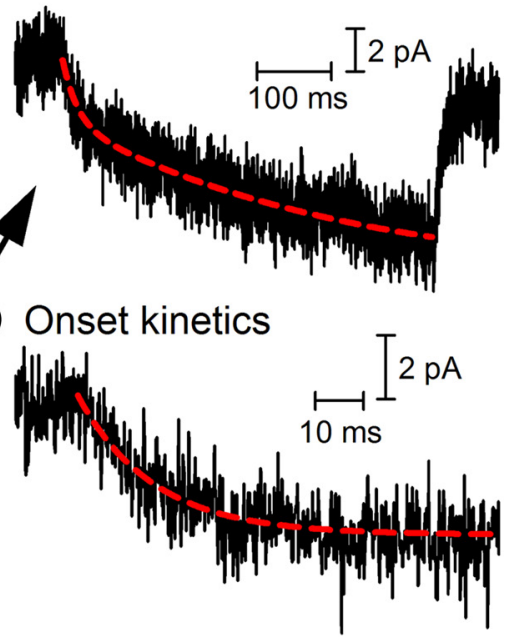

B

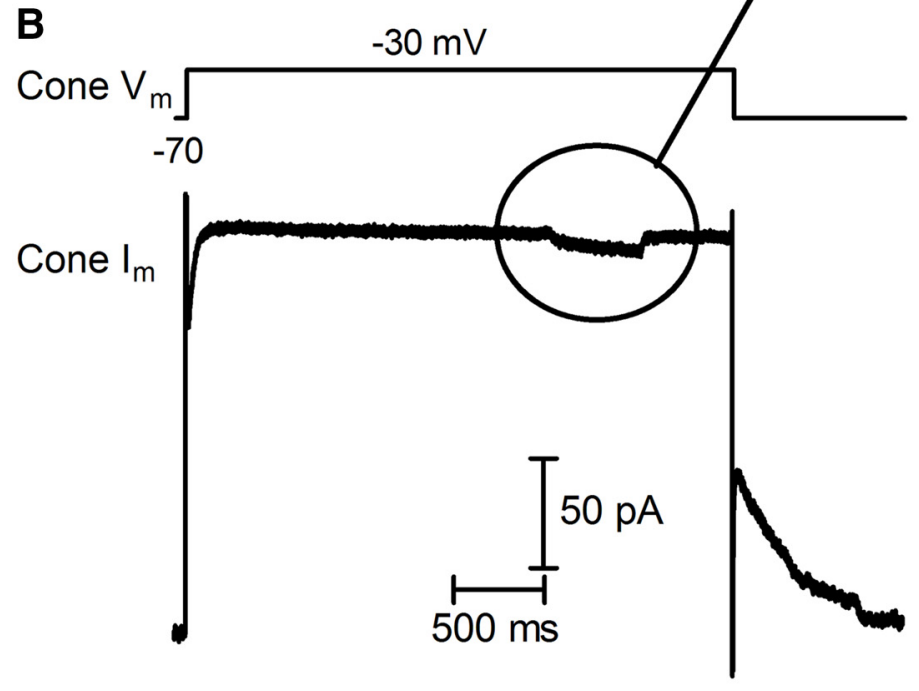

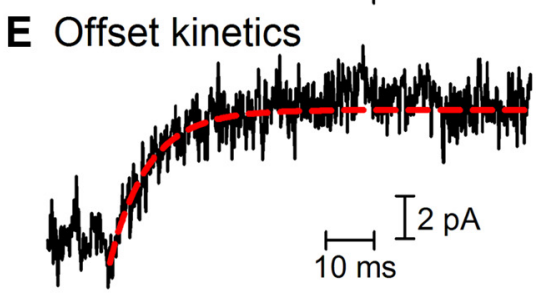

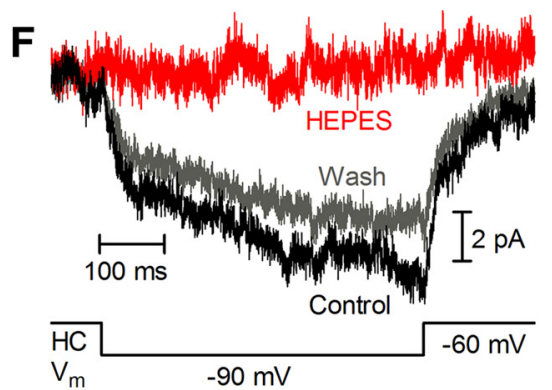

Figure 1. Testing for an ephaptic connection in cone/HC pairs: protocol and feedback currents. $A$, The test step waveform applied to the voltage-clamped $\mathrm{HC}$ is shown at the top $\left(\mathrm{HC} \mathrm{V}_{\mathrm{m}}\right)$, and the resulting $\mathrm{HC}$ membrane current is shown beneath $\left(\mathrm{HCl}_{\mathrm{m}}\right.$ ). $\boldsymbol{B}$, Voltage protocol applied simultaneously to a voltage-clamped cone (Cone $\mathrm{V}_{\mathrm{m}}$ ) is shown at the top and the cone membrane current beneath $\left(\mathrm{Cone} \mathrm{I}_{\mathrm{m}}\right.$ ). Note the small inward current in the cone evoked by the hyperpolarizing step applied to the simultaneously voltage-clamped $\mathrm{HC}$ (circle). $C$, Expanded view of the inward current evoked by HC feedback in the cone and fit with a double-exponential curve $\left(\tau_{1}=19.5 \mathrm{~ms}, 2.84 \mathrm{pA} ; \tau_{2}=384 \mathrm{~ms}, 7.52 \mathrm{pA}\right)$. D, E, Even more magnified views of the feedback current in the cone showing single exponential fits to onset $\left(\tau_{\text {on }}=15.6 \mathrm{~ms}\right)(\boldsymbol{D})$ and offset $\left(\tau_{\text {off }}=7.9 \mathrm{~ms}\right)(\boldsymbol{E})$ of the feedback-induced current. $\boldsymbol{F}$, Supplementing the bicarbonate-buffered superfusate with HEPES $(20 \mathrm{~mm})$ while maintaining the $\mathrm{pH}$ at 7.4 reversibly abolished feedback currents. Black trace represents control. Red trace represents HEPES. Gray trace represents wash. Data from a different $\mathrm{HC} /$ cone pair.

\section{Results}

Measurement of HC-to-cone feedback

As illustrated in Figure 1, to study feedback from HCs to cones, we voltage-clamped both a cone and $\mathrm{HC}$ at $-30 \mathrm{mV}$ for $2-3 \mathrm{~s}$ to simulate a period of darkness. We then hyperpolarized the HC to $-90 \mathrm{mV}(0.5 \mathrm{~s})$ to simulate a saturating bright flash of light. Finally, we returned the $\mathrm{HC}$ holding potential to $-30 \mathrm{mV}$ for another $0.5 \mathrm{~s}$. In addition to membrane currents in the $\mathrm{HC}$ itself, hyperpolarizing the HC stimulated an inward feedback current in the presynaptic cone (Fig. $1 B-D$ ). At a holding potential of -30 $\mathrm{mV}\left(-39 \mathrm{mV}\right.$ after correcting for the LJP), the L-type $\mathrm{I}_{\mathrm{Ca}}$ in cones is partially activated. The inward feedback current in the cone (Fig. $1 B-D$ ) results from a feedback-induced increase in $\mathrm{I}_{\mathrm{Ca}}$ at this potential caused by a negative shift in $\mathrm{I}_{\mathrm{Ca}}$ voltage dependence as well as an overall increase in $\mathrm{I}_{\mathrm{Ca}}$ amplitude (Verweij et al., 1996; Cadetti and Thoreson, 2006). Inward feedback currents measured in cones voltage-clamped at $-30 \mathrm{mV}$ averaged $-8.3 \pm 1.2$ pA $(N=27)$. We averaged feedback currents in each cell pair from 3 to 10 trials. To enhance $\mathrm{I}_{\mathrm{Ca}}$ activation and thereby increase feedback current amplitude, we sometimes set the cone holding potential to a more positive potential of $-20 \mathrm{mV}(-29 \mathrm{mV}$ after correcting for the LJP). Inward feedback currents measured in cones at a holding potential of $-20 \mathrm{mV}$ averaged $-9.0 \pm 1.0 \mathrm{pA}$ $(N=20)$. Like feedback-induced changes in cone $\mathrm{I}_{\mathrm{Ca}}$ observed in other studies (Hirasawa and Kaneko, 2003; Cadetti and Thoreson, 2006), inward feedback currents were abolished by $\mathrm{Cd}^{2+}$ $(200 \mu \mathrm{M} ; N=4)$ and inhibited in a dose-dependent fashion by addition of the $\mathrm{pH}$ buffer, HEPES, to the superfusate $(1 \mathrm{mM}$, $30.6 \pm 12.6 \%$ inhibition, $N=11 ; 10 \mathrm{~mm}, 86.5 \pm 3.9 \%, N=5 ; 20$ $\mathrm{mm}, 94.0 \pm 2.0 \%, N=8)$. At a concentration of $20 \mathrm{mM}$, HEPES typically abolished feedback (e.g., Fig. $1 F$ ), although in a few cells a small residual current still remained even at this concentration. Residual currents showed similar kinetics to control currents: fast time constants measured at onset and offset of feedback were not altered significantly by addition of $1 \mathrm{mM}$ HEPES (onset, $p=$ 0.098 ; offset, $p=0.273$ ). The mechanism by which changes in HC 
membrane potential alter free proton levels in the cone synaptic cleft appears to involve changes in the flux of bicarbonate ions across the HC membrane (Liu et al., 2013; Warren et al., 2016). Additional buffering by HEPES would not be expected to alter the rate of bicarbonate flux, and this may explain why HEPES had little effect on the speed of feedback. The noncompetitive $\mathrm{GABA}_{\mathrm{a} / \mathrm{c}}$ antagonist, picrotoxinin $(30 \mu \mathrm{M})$, did not cause a significant change in feedback current amplitude (picrotoxinin, $10.5 \pm$ $3.0 \mathrm{pA}$; control, $8.6 \pm 2.3 \mathrm{pA}, N=5, p=0.15$, paired $t$ test).

At onset of the hyperpolarizing step applied to the HC, inward feedback currents in cones increased with a time course that could typically be fit with a double exponential function. Figure $1 C$ shows a double exponential fit to the inward feedback current evoked in a cone by a hyperpolarizing step applied to the HC $\left(\tau_{1}=19.5 \mathrm{~ms}, \tau_{2}=384 \mathrm{~ms}\right)$. We saw two exponential components in 30 of 33 experiments conducted when cones were held at $-30 \mathrm{mV}$ and in 24 of 24 experiments when cones were held at $-20 \mathrm{mV}$. Time constants for the slow component averaged $223 \pm 26.7 \mathrm{~ms}(N=30)$ and $174 \pm 24.0 \mathrm{~ms}(N=24)$ when cones were held at -30 and $-20 \mathrm{mV}$, respectively. We held cones at -30 or $-20 \mathrm{mV}$ for $2-3 \mathrm{~s}$ before applying a hyperpolarizing voltage step to a postsynaptic $\mathrm{HC}$ to test for feedback. In most cases, this interval was sufficient for voltage-dependent currents in the cone to stabilize (e.g., Fig. 1B), but some cones showed continued slow inward or outward current changes even after 2-3 s; these slow changes likely impacted measurement of the slow time constant.

To determine whether feedback currents were fast enough to result from an ephaptic mechanism, we wanted to identify the fastest initial change in feedback currents. To do so, we fit the earliest part of the feedback current using a single exponential function. We fit the first 20-40 ms of the cone feedback current observed at onset of the HC voltage step, adjusting the fitting region to find the fastest time constant that could accurately describe the initial portion of the feedback current. In the example shown in Figure $1 D$, the initial increase in inward feedback current was fit with a fast time constant of $15.6 \mathrm{~ms}$. Overall, fast time constants measured in this way averaged $17.3 \pm 1.6 \mathrm{~ms}(N=33)$ and $14.5 \pm 1.3 \mathrm{~ms}(N=24)$ when cones were held at -30 and $-20 \mathrm{mV}$, respectively.

At offset of the hyperpolarizing step applied to the $\mathrm{HC}$, the feedback current diminished. The decrease in feedback also typically followed a two exponential time course. A second component was observed in 21 of 30 experiments conducted when the cone was held at $-30 \mathrm{mV}$ and 23 of 25 experiments when the cone was held at $-20 \mathrm{mV}$. Slow time constants averaged $120 \pm$ $21.1 \mathrm{~ms}(N=21)$ and $196 \pm 23.5 \mathrm{~ms}(N=22)$ when cones were held at -30 and $-20 \mathrm{mV}$, respectively. As with onset of the feedback current, we adjusted the fitting region within the first 20-40 ms following offset of the HC voltage step to find the region where a single exponential fit yielded the fastest change in feedback current (Fig. 1E). Fast time constants for offset of the feedback current averaged $16.3 \pm 1.6 \mathrm{~ms}(N=33)$ and $15.2 \pm 1.5$ $\mathrm{ms}(N=24)$ when cones were held at -30 and $-20 \mathrm{mV}$, respectively. The fast time constants observed at onset and offset of feedback did not differ significantly from one another $(-30 \mathrm{mV}$, $p=0.47 ;-20 \mathrm{mV}, p=0.36)$.

On the assumption that an ephaptic mechanism should be less sensitive to temperature than a chemical mechanism, we manipulated bath temperature using an inline Peltier device to cool the superfusate by $4^{\circ} \mathrm{C}-5^{\circ} \mathrm{C}$. Feedback slowed as the superfusate was cooled with a $\mathrm{Q}_{10}$ for feedback time constants (measured at cone $\mathrm{V}_{\mathrm{m}}=-20 \mathrm{mV}$ ) of $\sim 3$ (feedback current onset, $3.85 \pm 0.54, N=$
5; feedback current offset, $2.60 \pm 0.50$; combined average, $3.22 \pm$ 0.40 ). However, the time constants for $\mathrm{I}_{\mathrm{Ca}}$ offset at termination of $100 \mathrm{~ms}$ step to $-20 \mathrm{mV}$ showed a similar $\mathrm{Q}_{10}(2.70 \pm 0.95, N=$ 9), consistent with reports on L-type channels in other preparations (Cota et al., 1983; Cavalié et al., 1985). Because $\mathrm{Ca}^{2+}$ channel $\mathrm{Q}_{10}$ values did not differ significantly from feedback $\mathrm{Q}_{10}$ values (comparison with feedback offset, $p=0.94$, unpaired $t$ test; comparison with feedback onset, $p=0.42$ ), these experiments did not help us to distinguish between chemical and ephaptic mechanisms.

\section{Measurement kinetics}

Measurements of feedback time constants are limited by the speed at which a voltage step applied to the HC produces a change in cone $\mathrm{Ca}^{2+}$ channel activity that can in turn be detected in the voltage-clamped cone. Measurements are thus limited by three factors: (1) the speed at which the membrane voltage changes at the synaptic terminus of the $\mathrm{HC}$ dendrite in response to a voltage step (determined by HC voltage-clamp speed); (2) the speed at which voltage changes in the cone terminal activate or deactivate $\mathrm{Ca}^{2+}$ channels; and (3) the speed at which feedback-induced changes in $\mathrm{I}_{\mathrm{Ca}}$ can be measured in the voltage-clamped cone (determined by cone voltage-clamp speed). We consider each of these factors below.

HCs are large neurons connected to neighboring HCs by gap junctions. To examine the speed at which the HC membrane potential actually changes in response to an applied voltageclamp step, we recorded from single HCs simultaneously using two patch-clamp electrodes (inset, Fig. 2A). One electrode was used to apply voltage steps via voltage clamp, whereas the other electrode was used to monitor the resulting membrane potential change in current-clamp mode but with no applied current. When a voltage step was applied to a voltage-clamped $\mathrm{HC}$, the membrane current typically exhibited a biexponential charging curve (Fig. 2A). The accompanying voltage change measured by current clamp rose with a time course that was best described by a single exponential (Fig. 2A). The time constants for voltage changes measured by current clamp in HCs $(2.23 \pm 0.34 \mathrm{~ms}$ with no $\mathrm{R}_{\mathrm{s}}$ compensation, $N=5 ; 1.51 \pm 0.38 \mathrm{~ms}$ after compensating for $70 \%$ of the $\mathrm{R}_{\mathrm{s}}, N=5$ ) closely matched the second time constant of the capacitative current decline measured simultaneously in voltage clamp $\left(2.35 \pm 0.40 \mathrm{~ms}\right.$ with no $\mathrm{R}_{\mathrm{s}}$ compensation, $N=$ $5 ; 1.44 \pm 0.25 \mathrm{~ms}$ after $70 \% \mathrm{R}_{\mathrm{s}}$ compensation, $N=5$; paired $t$ test, $p=0.74, N=10)$. As a measure of the speed at which the HC membrane potential changed in response to the applied step, we therefore used the slower second time constant from the HC charging curve. In the sample of cell pairs where feedback currents were measured with cone holding potentials of -30 or -20 $\mathrm{mV}$, the second time constant measured from capacitative currents in voltage-clamped HCs $\left(\tau_{\mathrm{HC}}\right)$ averaged $1.95 \pm 0.15 \mathrm{~ms}$ $(N=33)$ and $2.22 \pm 0.22 \mathrm{~ms}(N=24)$, respectively. For comparison, the fast voltage-clamp time constant from capacitative currents in these same cells averaged $1.03 \pm 0.10 \mathrm{~ms}(N=33)$ and $1.18 \pm 0.14 \mathrm{~ms}(N=24)$ for -30 and $-20 \mathrm{mV}$ trials, respectively, $\mathrm{HCs}$ are less strongly coupled in retinal slices than in whole retina and so their input resistance can be relatively high $(322 \pm 40 \mathrm{M} \Omega$, $N=27$ ). We found no significant correlation between $\mathrm{HC}$ input resistance and feedback time constants $\left(r^{2}=0.0024\right.$; slope, $p=0.73)$

Cones have a large capacitance due to the generous membrane in-foldings of their outer segments. Nevertheless, the cone seems to behave like a single isopotential compartment in the sense that the decline in transient capacitance current was well described by 
A
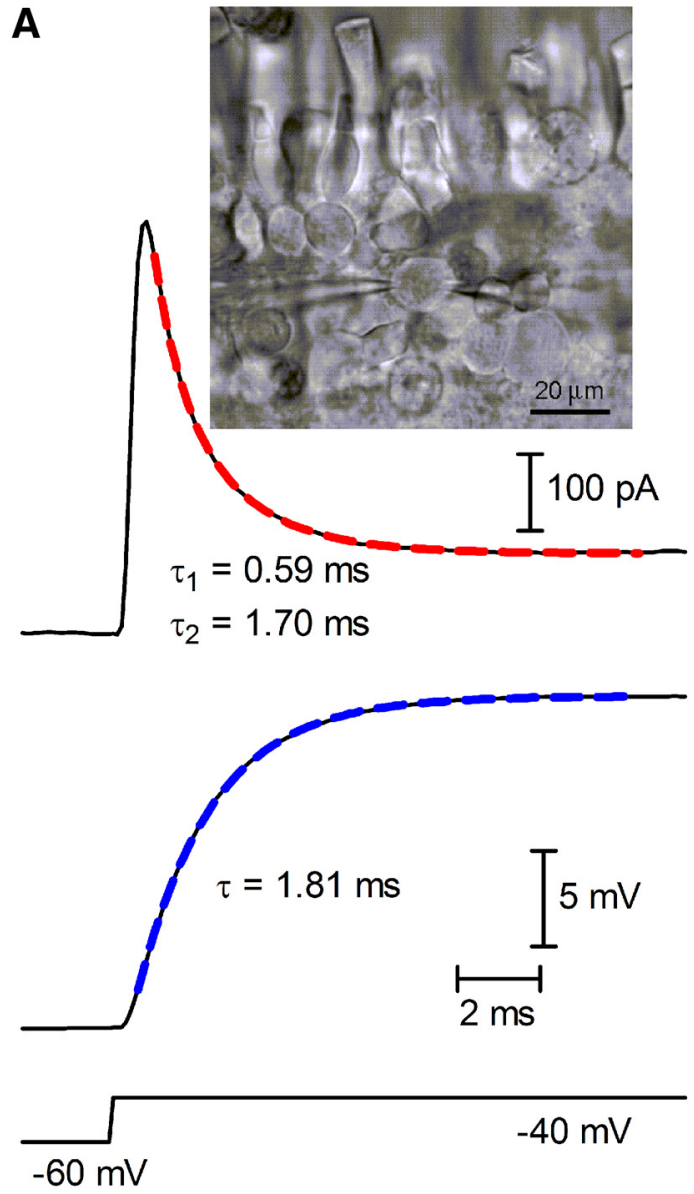

B

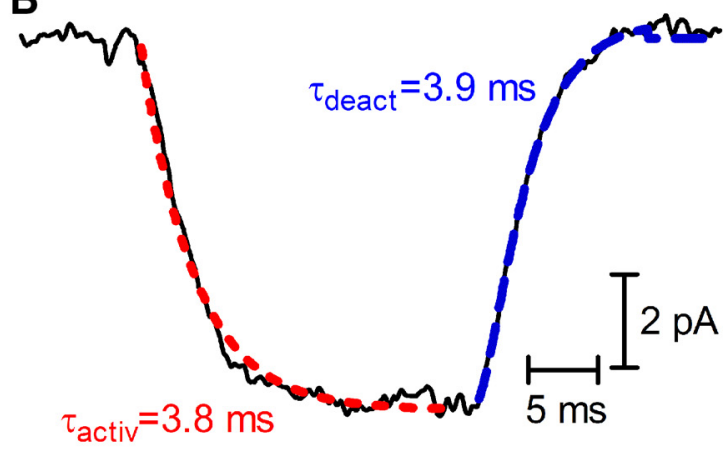

$-25 \mathrm{mV}$

$-30 \mathrm{mV}$

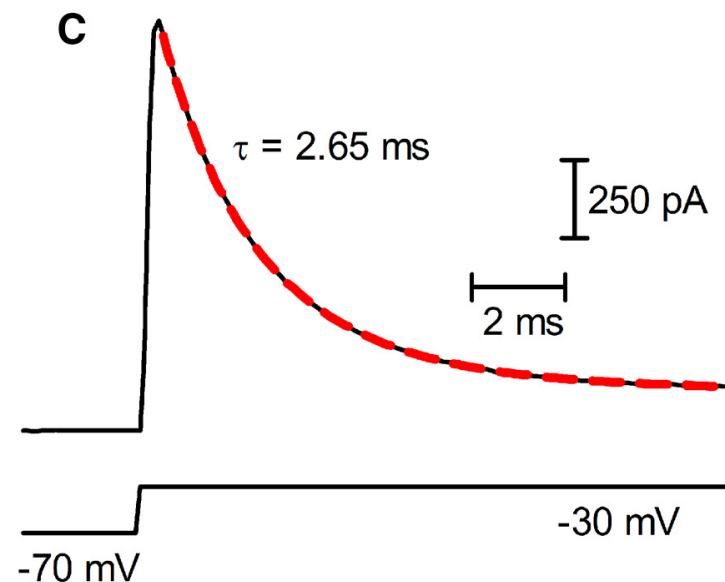

Figure 2. Measurement time resolution in cone/HC pairs. $\boldsymbol{A}$, Simultaneous recording from a single $\mathrm{HC}$ with two patch-clamp electrodes. One electrode was used to apply voltage steps via voltage clamp, whereas the other electrode was used to monitor the resulting membrane potential in current-clamp mode with zero current injection. Inset, Bright-field image of an HC with two pipettes. Top, Current measured by the voltage-clamp pipette during a voltage step from -60 to $-40 \mathrm{mV}$. The capacitative current declined with a biexponential time course: $\tau_{1}=0.59 \mathrm{~ms}$ and $\tau_{2}=1.70$ $\mathrm{ms}$. The accompanying voltage change measured with the current-clamp pipette rose with a time course that was best described by a single exponential with $\tau=1.81$ ms. $B, I_{C a}$ kinetics measured in a cone by applying a $5 \mathrm{mV}$ voltage step for $25 \mathrm{~ms}$ before returning to the command potential of $-30 \mathrm{mV}$. To record passive capacitative and resistive currents, the cone was voltage-clamped at $-70 \mathrm{mV}$ and a $5 \mathrm{mV}, 25 \mathrm{~ms}$ depolarizing test step was applied. $\mathrm{I}_{\mathrm{h}}$ was blocked by including $2 \mathrm{~mm} \mathrm{CsCl}$ in the bathing solution. The plotted $\mathrm{I}_{\mathrm{Ca}}$ (dark solid trace) is the average of 100 trials after removal of the passive currents. The best-fitting single exponential curves for activation (dashed red, $\tau_{\text {activ }}$ ) and deactivation (dashed blue, $\tau_{\text {deactiv }}$ ) had time constants of 3.8 and 3.9 ms, respectively. $\boldsymbol{C}$, Net passive membrane current (dark solid trace), comprised of capacitance and resistance components, in response to a voltage-clamp step from a steady command potential of - $70 \mathrm{mV}$ to $-30 \mathrm{mV}$. The charging current curve was fit with a single exponential (solid red) whose time constant was $2.65 \mathrm{~ms}$.

a single exponential (Fig. 2C). Cone voltage-clamp time constants $\left(\tau_{\text {cone }}\right)$ averaged $2.07 \pm 0.15 \mathrm{~ms}(N=33)$ and $1.77 \pm 0.20$ $\mathrm{ms}(N=24)$ in the samples where cones were voltage-clamped at -30 and $-20 \mathrm{mV}$, respectively.

Photoreceptor terminals contain CaV1.4 L-type $\mathrm{Ca}^{2+}$ channels (Morgans, 2001; Mansergh et al., 2005) and heterologously expressed mouse CaV1.4 channels can activate rapidly with a time constant of $0.6 \mathrm{~ms}$ in response to a strong depolarizing step (Baumann et al., 2004). However, $\mathrm{Ca}^{2+}$ channels activate more slowly with weaker depolarizing steps (Corey et al., 1984). To measure $\mathrm{I}_{\mathrm{Ca}}$ kinetics in salamander cones, we voltage-clamped them at $-30 \mathrm{mV}$ and applied a $5 \mathrm{mV}$ depolarizing step for $25 \mathrm{~ms}$. We repeated this weak test step 100 times and averaged the resulting currents. To subtract passive capacitative and resistive currents, we clamped the same cones at $-70 \mathrm{mV}$ and repeated application of the $5 \mathrm{mV}$ test step for 100 trials. In addition to including $\mathrm{Cs}^{+}$and TEA in the patch pipette solution, we added 2 $\mathrm{mm} \mathrm{CsCl}$ to the bathing solution to block $\mathrm{I}_{\mathrm{h}}$ currents that might be active at more negative potentials. After subtracting the passive currents, we observed a small inward $\mathrm{I}_{\mathrm{Ca}}$ averaging $5.8 \pm 1.9$ $\mathrm{pA}(N=5)$. We fit $\mathrm{I}_{\mathrm{Ca}}$ activation at onset of the depolarizing step and deactivation at step offset with single exponentials. In the example shown in Figure $2 B, \mathrm{I}_{\mathrm{Ca}}$ activated with a time constant of $3.8 \mathrm{~ms}$ and deactivated with a time constant of $3.9 \mathrm{~ms}$. On average, $\mathrm{I}_{\mathrm{Ca}}$ activated with a time constant of $3.06 \pm 0.22 \mathrm{~ms}$ and deactivated with a time constant of $4.18 \pm 0.65 \mathrm{~ms}(N=5)$. These time constants incorporate both the speed of cone voltage clamp as well as any additional contribution from channel activation or deactivation kinetics. By subtracting the cone voltage-clamp time constants from the $\mathrm{I}_{\mathrm{Ca}}$ time constants for each cone in this sample, we found that while cone voltage-clamp speed accounted for some of the observed $\mathrm{I}_{\mathrm{Ca}}$ kinetics, channel activation kinetics $\left(\tau_{\text {activ }}\right)$ added an additional $0.83 \pm 0.38 \mathrm{~ms}$ and deactivation $\left(\tau_{\text {deactiv }}\right)$ added $1.96 \pm 0.61 \mathrm{~ms}(N=5)$.

Together, the sum of these three time constants $\left(\tau_{\mathrm{HC}}+\right.$ $\tau_{\text {cone }}+\tau_{\text {activ }}$ or $\tau_{\text {HC }}+\tau_{\text {cone }}+\tau_{\text {deactiv }}$ ) represents the fastest speed at which a step applied to the $\mathrm{HC}$ would be expected to produce a measurable change in cone $\mathrm{I}_{\mathrm{Ca}}$ due to feedback. Summing these values yielded average resolution limits of 4.85 and $4.82 \mathrm{~ms}$ for onset of feedback in experiments where cones were voltageclamped at -30 and $-20 \mathrm{mV}$, respectively. These values compare with average time constants for feedback onset of 17.3 and 14.5 

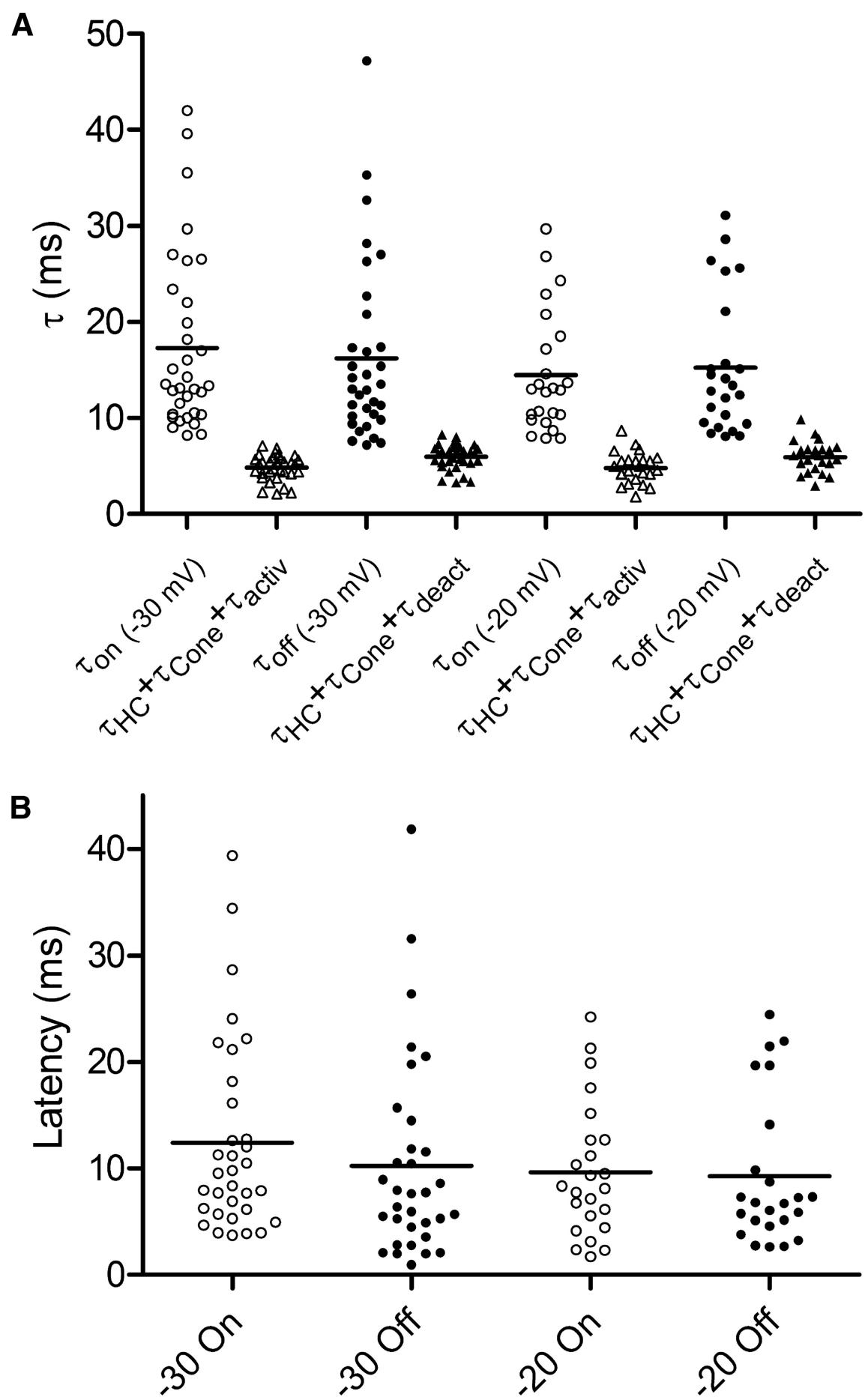

Figure 3. Comparisons of feedback and measurement kinetics in cone/HC pairs. A, Scatter plot comparing fast feedback time constants and measurement kinetics in cone/HC pairs. At onset of $\mathrm{HC}$-to-cone feedback evoked by stepping the $\mathrm{HC}$ from -30 to $-90 \mathrm{mV}$, the fast time constant averaged $17.3 \pm 1.6 \mathrm{~ms}\left(\tau_{\text {on }},-30 \mathrm{mV}, N=33\right)$ when cones were held at $-30 \mathrm{mV}\left(\tau_{\text {on }},-30\right.$ $\mathrm{mV})$ and $14.5 \pm 1.3 \mathrm{~ms}(N=24)$ when cones were held at $-20 \mathrm{mV}\left(\tau_{\mathrm{on}}-20 \mathrm{mV}\right)$. At offset of the HC test step, fast feedback time constants averaged $16.3 \pm 1.6 \mathrm{~ms}(N=33)$ and $15.2 \pm 1.5 \mathrm{~ms}(N=24)$ when cones were held at $-30\left(\tau_{\text {off }},-30 \mathrm{mV}\right)$ and -20 $\mathrm{mV}\left(\tau_{\text {off }}-20 \mathrm{mV}\right)$, respectively. The time resolution for these recordings was limited by the sum of the charging time constants in the cone $\left(\tau_{\text {cone }}\right)$ and $\mathrm{HC}\left(\tau_{\mathrm{HC}}\right)$ plus the time required for activation $\left(\tau_{\text {activ }}\right)$ or deactivation of $\mathrm{I}_{\mathrm{Ca}}\left(\tau_{\text {deactiv }}\right) \cdot \tau_{\mathrm{HC}}+\tau_{\text {cone }}+\tau_{\text {activ }}=$ $4.85 \pm 0.23 \mathrm{~ms}$ and $4.82 \pm 0.33 \mathrm{~ms}$ for trials in which the cone $\mathrm{V}_{\mathrm{m}}=-30 \mathrm{mV}$ and $-20 \mathrm{mV}$, respectively. $\tau_{\mathrm{HC}}+\tau_{\text {cone }}+$ $\tau_{\text {deactiv }}=5.98 \pm 0.23$ and $5.95 \pm 0.33 \mathrm{~ms}$ for trials in which the cone $V_{\mathrm{m}}=-30 \mathrm{mV}$ and $-20 \mathrm{mV}$, respectively. The differences between the feedback time constants ( $\tau_{\text {on }}$ or $\left.\tau_{\text {off }}\right)$ and corresponding measurement kinetics $\left(\tau_{\mathrm{HC}}+\tau_{\text {cone }}+\tau_{\text {activ }}\right.$ or $\tau_{\mathrm{HC}}+$ $\tau_{\text {cone }}+\tau_{\text {deactiv }}$ ) were significant for all four comparisons ( $t$ tests, paired comparisons; $\left.p<0.0001\right)$. $\boldsymbol{B}$, The latencies for HC-to-cone feedback in individual cell pairs calculated by subtracting measurement time constants $\left(\tau_{\mathrm{HC}}+\tau_{\text {cone }}+\tau_{\text {activ }}\right.$ or $\tau_{\mathrm{HC}}+\tau_{\text {cone }}+$ $\tau_{\text {deactiv }}$ ) from fast feedback time constants $\left(\tau_{\text {on }}\right.$ or $\tau_{\text {off }}$ ). The latencies for feedback measured at onset of the hyperpolarizing $\mathrm{HC}$ step averaged $12.5 \pm 1.6(\mathrm{~N}=33)$ and $9.7 \pm 1.3 \mathrm{~ms}(\mathrm{~N}=24)$ for -30 and $-20 \mathrm{mV}$ trials, respectively. The $\mathrm{ms}$ in -30 and $-20 \mathrm{mV}$ trials. At offset, feedback time constants averaged 16.3 and $15.1 \mathrm{~ms}$ in -30 and $-20 \mathrm{mV}$ trials with corresponding time resolution limits (incorporating $\mathrm{I}_{\mathrm{Ca}}$ deactivation rather than activation) of 5.98 and 5.95 ms. Figure $3 A$ shows a scatter plot of the onset and offset time constants for feedback compared with summed time constants for $\tau_{\mathrm{HC}}+\tau_{\text {cone }}$ together with either $\tau_{\text {activ }}$ or $\tau_{\text {deactiv }}$. The differences between the feedback time constants $\left(\tau_{\text {on }}\right.$ or $\tau_{\text {off }}$ at cone holding potentials of -30 or $-20 \mathrm{mV}$ ), and the corresponding measurement kinetics $\left(\tau_{\mathrm{HC}}+\tau_{\text {cone }}+\tau_{\text {activ }}\right.$ or $\tau_{\mathrm{HC}}+\tau_{\text {cone }}+\tau_{\text {deactiv }}$ ) were highly significant for all four paired comparisons ( $t$ tests, $p<0.0001)$.

If fast feedback is due to an ephaptic mechanism that operates with no delay, then the observed kinetics of feedback should be limited only by measurement kinetics. If so, feedback kinetics should be correlated with measurement kinetics. However, we found no significant correlation between the fast feedback time constants at onset $\left(\tau_{\text {on }}\right)$ or offset $\left(\tau_{\text {off }}\right)$ of the HC step compared with the overall voltage-clamp speed (i.e., the summed $\mathrm{HC}$ and cone membrane time constants in each pair) $\left(\tau_{\text {on }}, R^{2}<0.0001 ; \tau_{\text {off }}, R^{2}=\right.$ $0.0017, N=58$ ). If kinetics of feedback currents are limited by measurement kinetics, then speeding up measurement capabilities should also speed up the measured feedback currents. We therefore tested whether compensating for $70 \%$ of the $\mathrm{R}_{\mathrm{s}}$ in both the cone and $\mathrm{HC}$ pipettes speeded up feedback kinetics. Shortening the cone and $\mathrm{HC}$ time constants improved overall measurement resolution by $\sim 2.8$ ms. However, in cell pairs where we compared recordings before and after $70 \% \mathrm{R}_{\mathrm{s}}$ compensation, feedback currents were actually slightly (but not significantly) slower after $\mathrm{R}_{\mathrm{s}}$ compensation ( $\tau_{\text {on }}, 1.3 \pm$ $2.0 \mathrm{~ms}$ slower after $\mathrm{R}_{\mathrm{s}}$ compensation, $p=$ $0.52 ; \tau_{\text {off }}, 0.1 \pm 2.5 \mathrm{~ms}$ slower after $R_{s}$ compensation, $p=0.98, N=12$ pairs, paired $t$ tests). Thus, contrary to predictions of an ephaptic effect, the measured speed of feedback was not limited by voltage-clamp speed.

We defined the latency for feedback as the difference calculated by subtracting feedback time constants ( $\tau_{\text {on }}$ or $\tau_{\text {off }}$ ) from

average latencies for feedback measured at offset were $10.3 \pm 1.6$ and $9.3 \pm 1.4 \mathrm{~ms}$ for -30 and $-20 \mathrm{mV}$ trials, respectively. These values were all significantly greater than zero (one sample $t$ test, $p<0.0001$ ). 
the summed time constants for temporal resolution $\left(\tau_{\mathrm{HC}}+\right.$ $\tau_{\text {Cone }}+$ either $\tau_{\text {activ }}$ or $\tau_{\text {deactiv }}$ ) in each cell pair. If an ephaptic mechanism is responsible for the fast component, then latency values should cluster around $0 \mathrm{~ms}$. However, latencies for feedback measured at onset of the hyperpolarizing HC step averaged $12.5 \pm 1.6(N=33)$ and $9.7 \pm 1.3 \mathrm{~ms}(N=24)$ for -30 and -20 $\mathrm{mV}$ trials, respectively (Fig. $3 B$ ). The average latencies for feedback measured at offset were $10.3 \pm 1.6$ and $9.3 \pm 1.4 \mathrm{~ms}$ for -30 and $-20 \mathrm{mV}$ trials, respectively. Because distributions were skewed, the median values offer a better representation of the central tendencies of the data. The median latencies were slightly shorter: 9.6 and $8.2 \mathrm{~ms}$ for -30 and $-20 \mathrm{mV}$ trials at onset and 7.6 and $6.8 \mathrm{~ms}$ for -30 and $-20 \mathrm{mV}$ trials at offset, respectively.

\section{Modeling and simulations}

For paired recordings, we selected cones that were immediately above or displaced laterally from the $\mathrm{HC}$ body by one cell diameter $(25 \mu \mathrm{m})$ or less. To estimate a membrane length constant in $\mathrm{HCs}$, we calculated membrane resistivity by dividing the average $\mathrm{HC}$ input resistance $(322 \mathrm{M} \Omega$ ) by the average membrane capacitance $\left(42 \mathrm{pF}\right.$ at $\left.1 \mu \mathrm{F} / \mathrm{cm}^{2}\right)$ to obtain a value of $13,500 \Omega-\mathrm{cm}^{2}$. This calculation probably underestimates the true membrane resistivity because it ignores coupling among $\mathrm{HCs}$ that should reduce the total input resistance but have minimal effects on whole-cell capacitance measurements. Cytoplasmic resistivity values typically range from 100 to $200 \Omega$-cm (Pilwat and Zimmermann, 1985; Shelton, 1985; Oltedal et al., 2009; Fry et al., 2012). At their termination, HC dendrites can be as narrow as $200 \mathrm{~nm}$ but widen considerably as they approach the cell body (Lasansky, 1973). Choosing a value of $200 \Omega$-cm for resistivity and a dendritic diameter of $200 \mathrm{~nm}$ yields a length constant of $260 \mu \mathrm{m}$. Regions of larger diameter would exhibit longer length constants. These calculations suggested that $\mathrm{HC}$ patch pipettes were typically $<0.1$ length constant from the cone/HC synapses during paired recordings.

To examine questions of space clamp further, we developed a mathematical model to simulate a voltage step applied to the HC soma and evaluated the time course and magnitude of the membrane voltage at the synaptic tip of the HC dendrite. The dendrite was modeled as a passive, leaky cable with circular cross-section of radius, $a$, and length, $L$. The dendritic membrane was assumed to have uniform resistivity of $R_{m}=13,500 \Omega-\mathrm{cm}^{2}$, capacitance per unit area $C_{m}=1 \mu \mathrm{F} / \mathrm{cm}^{2}$, and cytoplasmic resistivity of 200 $\Omega$-cm. According to classical cable-equation theory, the electrotonic space constant, $\lambda=\sqrt{a R_{m} / \rho}$; the resistance per unit length for longitudinal (axial) spread of current, $r_{i}=\rho / \pi a^{2}$; and the membrane time constant, $\tau_{m}=R_{m} C_{m}$. We define $R_{t}$ as the total resistance to ground from the dendritic terminus via the synaptic cleft. The significance of $R_{t}$ with respect to determining the membrane potential at the dendritic terminus, $V_{L} \stackrel{\text { def }}{=} V(L, t)$, can be

appreciated by considering the regime in which $\mathrm{L} \ll \lambda$ (e.g., $\mathrm{L}=$ $0.1 \lambda$ ). In this regime, the steady-state membrane potential at the dendritic terminus is approximately given by the following:

$$
V_{L}^{\infty}=\frac{R_{t}}{r_{i} L+R_{t}} \Delta v .
$$

Equation 1 shows that, in order for the intracellular dendritic voltage at the terminus $(x=L)$ to be a substantial fraction of $\Delta v$, $R_{t}$ has to be large compared with $r_{i} L$; that is, $R_{t}=10 r_{i} L$, which would give $V_{L}^{\infty} \cong 0.9 \Delta v$.

We solved analytically, by a Fourier transform method, the dendritic cable equation for the membrane potential $V(x, t)$ with two boundary conditions: at $x=0$, we have $V(0, t)=\Delta v$ (for $t \geq 0)$; and at $x=L$ we have $-\left.r_{i} \frac{d V(x, t)}{d x}\right|_{x=L}=\frac{V(L, t)}{R_{t}}$. The second boundary condition says that the longitudinal current at the dendritic tip is equal to the current that flows to ground through its membrane via the synaptic cleft. The Fourier transform of the dendritic membrane potential at the dendritic terminus $\tilde{V}(L, \omega)$ is given by the following:

$$
\tilde{V}(L, \omega)=\frac{1}{i \omega}\left\{\frac{R_{t}}{r_{i} \Lambda(\omega) \sinh \frac{L}{\Lambda(\omega)}+R_{t} \cosh \frac{L}{\Lambda(\omega)}}\right\} \Delta v,
$$

where

$$
\Lambda(\omega)=\frac{\lambda}{\sqrt{1+i \omega \tau_{m}}} .
$$

In Equation 2, 1/i $\omega$ is the Fourier transform of the integral operator. Consequently, we solved for $V(L, t)$ by taking the inverse Fourier transform of the term in curly bracket in Equation 2, as follows:

$$
\tilde{f}(\omega) \stackrel{\text { def }}{=}\left\{\frac{R_{t}}{r_{i} \Lambda(\omega) \sinh \frac{L}{\Lambda(\omega)}+R_{t} \cosh \frac{L}{\Lambda(\omega)}}\right\},
$$

and then integrating over time. We computed the inverse Fourier transform of $\tilde{f}(\omega)$ by using MATLAB's ifft function in a parameter regime in which the discrete Fourier transform provides an excellent approximation to the Fourier integral transform.

Because $\Delta v$ times the expression in curly brackets in Equation 2 is the derivative of the response to a voltage-clamp step, it is analogous to an impulse response function after a scaling that makes its integral equal to 1 . We refer to $f(t)$ as a pseudo-impulse response function. A good measure of the latency of response at the dendritic terminus to a voltage-clamp step at the HC soma is the first moment of this normalized pseudo-impulse response function:

$$
\tau_{d}=\frac{\int_{0}^{\infty} t f(t) d f}{\int_{0}^{\infty} f(x) d x},
$$

which is equivalent to $\tau_{d}=i \tilde{f}^{\prime}(0) / \tilde{f}(0)$.

Assuming $L=30 \mu \mathrm{m}$ and $a=100 \mathrm{~nm}$, the membrane potential at the tip of the dendrite evoked by a step applied to the soma has a latency $\tau_{\mathrm{d}}$ of $<0.1 \mathrm{~ms}$. Increasing dendritic radius, lowering cytoplasmic resistivity, or raising membrane resistivity all speed the voltage rise. To obtain latencies $\tau_{d}$ that approach values observed for HC-to-cone feedback currents $(>5 \mathrm{~ms}$ ), we had to increase the dendritic length to $>275 \mu \mathrm{m}$, far greater than the actual distance between the recording pipette and HC synapses. These simulations show that the slow time constants observed for feedback were not due to slow changes in voltage at the dendritic tips during an applied voltage step.

\section{Feedback and feedforward kinetics compared at the same cone/HC synapses}

Although the calculations above suggest that good voltage control can be maintained at cone/HC synapses, we were also able to demonstrate this directly by recording fast feedforward glutama- 
tergic synaptic transmission at these very same synapses. Feedforward glutamate release is a rapid process known to approach the limits of measurement speed. We compared kinetics of feedback and feedforward transmission because, if feedback is mediated by an ephaptic mechanism, it should be faster than chemical transmission occurring at the same synapse. At the beginning of each experiment, we typically applied a voltage step $(-70$ to $-10 \mathrm{mV})$ to the cone to test whether it was synaptically connected to the simultaneously voltage-clamped $\mathrm{HC}$. As shown previously $(\mathrm{Ca}-$ detti and Thoreson, 2006), feedback currents evoked by hyperpolarizing steps applied to HCs were consistently present in pairs where PSCs were evoked by depolarizing steps applied to cones but absent from pairs where PSCs could not be evoked. This indicates that feedback currents occurred the very same ribbon synapses as feedforward currents. As described previously in greater detail (Cadetti et al., 2005; Bartoletti et al., 2010; Van Hook and Thoreson, 2015), cone-driven HC PSCs are derived from release at a handful of ribbon synapses and show an initial fast transient inward current followed by a small sustained current (Fig. $4 A$, top). The number of ribbon synapses connecting a particular cone/HC pair can be estimated by dividing the peak amplitude of the maximal PSC by $46 \mathrm{pA} /$ ribbon (Bartoletti et al., 2010). Multiple lines of evidence show that PSCs at cone/HC synapses in salamander retina reflect a linear sum of individual quantal miniature PSCs (Cadetti et al., 2005, 2008; Rabl et al., 2005). One can therefore measure the kinetics of feedforward synaptic transmission at the cone synapse by integrating the $\mathrm{HC}$ PSC and then fitting the increase in PSC charge transfer with a double exponential function (Bartoletti et al., 2010). The initial fast component of this double exponential function reflects the rate of fast release of the readily releasable pool of vesicles at the ribbon base (Bartoletti et al., 2010; Van Hook and Thoreson, 2015; Thoreson et al., 2016). In the example shown in Figure $4 A$, the fast component of the PSC produced an increase in charge transfer that rose with an initial time constant of $2.1 \mathrm{~ms}$. Overall, the time constants for release measured from PSC charge transfer averaged $3.9 \pm 0.24 \mathrm{~ms}(N=18)$, slightly slower than release time constants obtained using capacitance techniques to measure vesicle fusion (2.4-2.7 ms) (Rabl et al., 2005). This is probably because exocytotic capacitance techniques measure only vesicle fusion, whereas PSC measurements also include the kinetics of glutamate diffusion and binding to receptors. Experiments using cyclothiazide to inhibit receptor desensitization and low-affinity antagonists to reduce receptor saturation have shown that there is little cross-desensitization or saturation between quanta (Cadetti et al., 2008; Pang et al., 2008), and so time constants for release measured from PSCs were not distorted significantly by nonlinear or saturating properties of the postsynaptic glutamate receptors.

Because they occur at the very same synapses, measurements of feedforward PSCs evoked in HCs by depolarizing steps applied to cones are limited in time resolution by the very same factors as measurements of feedback kinetics, including voltage-clamp speed of the two cells, electrotonic distance to the synapse, and $\mathrm{Ca}^{2+}$ channel kinetics. An ephaptic mechanism should occur without synaptic delay, and so the feedback current should show faster kinetics than feedforward chemical transmission, which also includes a small delay for release of synaptic vesicles. However, when measured at the same ribbon synapses, the fast component of the inward feedback current evoked in this cone (holding potential $=-20 \mathrm{mV}$ ) by a hyperpolarizing step applied to the $\mathrm{HC}(-30$ to $-90 \mathrm{mV})$ showed a time constant of $8.8 \mathrm{~ms}$, much slower than the time constant for feedforward synaptic

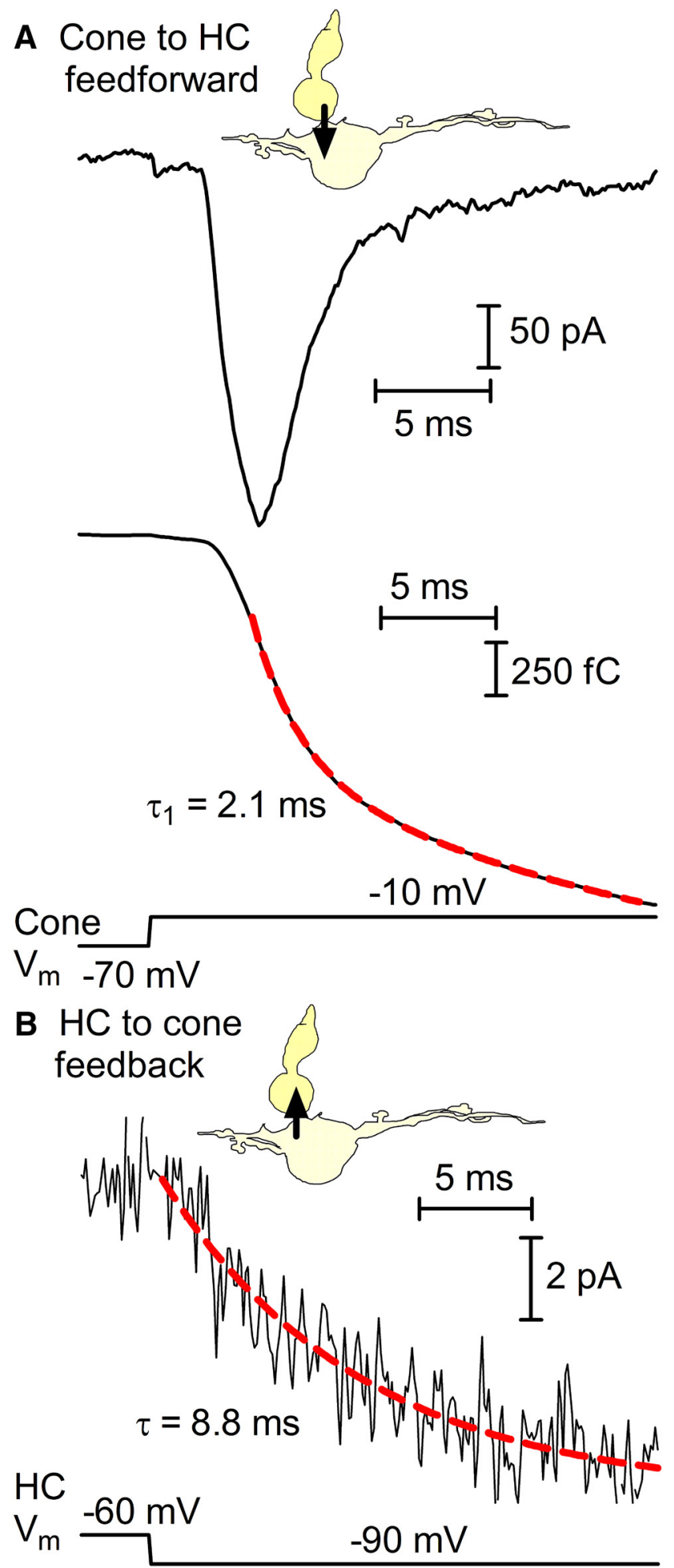

Figure 4. Comparison of cone-to-HC feedforward release and HC-to-cone inhibitory feedback at the same synapse. $A$, Top, PSC evoked in a voltage-clamped HC ( $-60 \mathrm{mV})$ by a depolarizing test step ( -70 to $-10 \mathrm{mV}$ ) applied to a simultaneously voltage-clamped cone. Bottom, Charge transfer of the same PSC fit with a double exponential function (amplitude $_{1}=719 \mathrm{fC}, \tau_{1}=2.1 \mathrm{~ms}$; amplitude $_{2}=1207 \mathrm{fC}, \tau_{2}=23.5 \mathrm{~ms}$ ). $\boldsymbol{B}$, Feedback current evoked in the same cone by a hyperpolarizing step applied to the same HC ( -60 to $-90 \mathrm{mV}$ ) and fit with a single exponential (amplitude $=7.7 \mathrm{pA}, \tau=8.8 \mathrm{~ms}$ ). Trace represents the average of 3 replicates. 

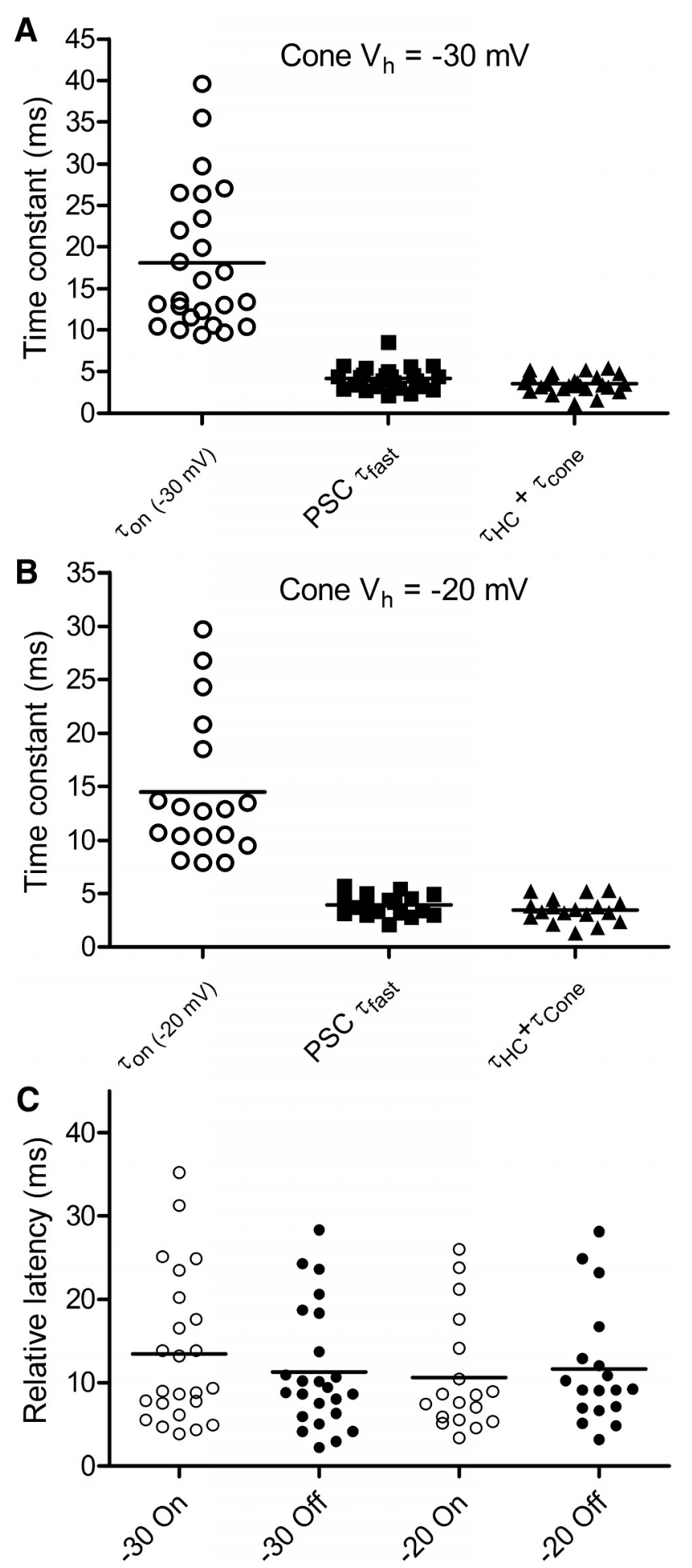

Figure 5. Comparisons of feedback, feedforward, and voltage-clamp kinetics at cone/HC synapses. Scatter plot comparing fast time constants for inhibitory feedback from HCs to cones $\left(\tau_{\text {on }}\right)$, fast rise in PSC charge transfer for feedforward synaptic release from cones to HCs (PSC $\left.\tau_{\text {fast }}\right)$, and summed $\mathrm{HC}$ and cone voltage-clamp time constants for each cell pair $\left(\tau_{\mathrm{HC}}+\tau_{\text {cone }}\right)$. At onset of the $\mathrm{HC}$ step from -30 to $-90 \mathrm{mV}$, fast feedback time constants averaged $18.1 \pm$ $1.7 \mathrm{~ms}(N=25)$ when cones were held at $-30 \mathrm{mV}\left(\boldsymbol{A}, \tau_{\text {on }},-30 \mathrm{mV}\right)$ and $14.5 \pm 1.7 \mathrm{~ms}(N=$ 18) when cones were held at $-20 \mathrm{mV}\left(\boldsymbol{B}, \tau_{o n^{\prime}}-20 \mathrm{mV}\right)$. Feedforward kinetics were measured at the same synapses by fitting the increase in PSC charge transfer with a double exponential function. Fast time constants for feedforward synaptic release averaged $4.2 \pm 0.28 \mathrm{~ms}(N=$ $25)$ in the sample where feedback was tested in cones held at $-30 \mathrm{mV}\left(\boldsymbol{A}, \mathrm{PSC} \tau_{\text {fast }}-30 \mathrm{mV}\right)$ and $3.9 \pm 0.24 \mathrm{~ms}(N=18)$ in the sample where feedback was tested in cones held at $-20 \mathrm{mV}$ (B, PSC $\tau_{\text {fast }}-20 \mathrm{mV}$ ). Like feedback, measurement of feedforward kinetics was limited by the release of $2.1 \mathrm{~ms}$ (Fig. 4B). Activation of cone $\mathrm{I}_{\mathrm{Ca}}$ by a step to -20 $\mathrm{mV}$ should be nearly as fast as stepping to $-10 \mathrm{mV}$ because the amplitude of $\mathrm{I}_{\mathrm{Ca}}$ evoked by a step to $-20 \mathrm{mV}$ is $\sim 90 \%$ of that attained by a step to $-10 \mathrm{mV}$ (Rabl et al., 2006). Even at a cone holding potential of $-30 \mathrm{mV}$, channel activation kinetics should add $<1$ ms (Fig. 2). Overall, fast feedforward time constants of synaptic release averaged $4.2 \pm 0.28(N=24$; Fig. $5 A)$ and $3.9 \pm$ $0.24 \mathrm{~ms}(N=18$; Fig. $5 B)$ in cell pairs where feedback was tested in cones clamped at -30 and $-20 \mathrm{mV}$, respectively. Feedback currents were much slower: fast feedback time constants measured in these same cell pairs at onset of the hyperpolarizing $\mathrm{HC}$ step $\left(\tau_{\text {on }}\right)$ averaged $18.2 \pm 1.8(N=24$; Fig. $5 A)$ and $14.5 \pm 1.6 \mathrm{~ms}$ $(N=18$; Fig. $5 B)$. PSCs were measured before activation of $\mathrm{R}_{s}$ compensation and so feedback trials with $70 \% \mathrm{R}_{\mathrm{s}}$ compensation were not included in these comparisons. The fact that feedforward time constants were 10-14 ms faster than feedback time constants measured at the same synapses shows very directly that measurements of feedback kinetics were not limited by measurement resolution or the speed at which voltage clamp could be achieved at these synapses. Summing $\tau_{\mathrm{HC}}$ and $\tau_{\text {cone }}$ yielded time constants of $3.6 \pm 0.22 \mathrm{~ms}(N=24 ;-30 \mathrm{mV}$ trials; Fig. $5 A)$ and $3.5 \pm 0.28 \mathrm{~ms}(N=18,-20 \mathrm{mV}$ trials; Fig. $5 B), \sim 0.5 \mathrm{~ms}$ faster than feedforward kinetics of release (Fig. $5 A, B$ ). This suggests that the kinetics of glutamate release at this synapse added $\sim 0.5$ $\mathrm{ms}$ to the kinetics dictated by voltage-clamp speed.

We next assessed feedback latency, which in this case we defined as the difference between the time constant for feedforward release (the fast component of PSC charge transfer: PSC $\tau_{\text {fast }}$ ) and time constants for onset $\left(\tau_{\text {on }}\right)$ or offset $\left(\tau_{\text {off }}\right)$ of inward feedback currents measured at the same synapses. Feedback at onset of the hyperpolarizing HC step was slower (i.e., longer latency) than feedforward release measured at the same synapses by an average of $13.5 \pm 1.8(N=24)$ and $10.6 \pm 1.6 \mathrm{~ms}(N=18)$ for -30 and $-20 \mathrm{mV}$ trials, respectively (Fig. $5 \mathrm{C}$ ). The mean latencies calculated for feedback at offset were $11.3 \pm 1.5$ and $11.6 \pm 1.7 \mathrm{~ms}$ for -30 and $-20 \mathrm{mV}$ trials, respectively (Fig. 3C). Median latencies were slightly shorter: 9.1 and $8.1 \mathrm{~ms}$ for -30 and $-20 \mathrm{mV}$ trials at onset and 9.1 and $9.2 \mathrm{~ms}$ for -30 and $-20 \mathrm{mV}$ trials at offset, respectively. These were similar to latency values obtained by comparing the predicted time resolution and feedback kinetics (Fig. 3B). These data show that negative feedback from HCs to cones is considerably slower than feedforward kinetics of release across the very same synapses, inconsistent with an ephaptic mechanism.

\section{Kinetics of HC-to-rod feedback}

Like cones, HCs also provide inhibitory feedback to $\mathrm{Ca}^{2+}$ channels in rod terminals (Thoreson et al., 2008), and so we measured the kinetics of HC feedback to rods in simultaneously voltage-

sum of the voltage-clamp time constants in the cone $\left(\tau_{\text {cone }}\right)$ and $\mathrm{HC}\left(\tau_{\mathrm{HC}}\right) . \tau_{\mathrm{HC}}+\tau_{\text {cone }}=$ $3.57 \pm 0.22 \mathrm{~ms}$ and $3.46 \pm 0.27 \mathrm{~ms}$ for trials in which cones were clamped for feedback measurements at $-30 \mathrm{mV}$ and $-20 \mathrm{mV}$, respectively. The differences between the time constants for inhibitory feedback $\left(\tau_{\text {on }}\right)$ and excitatory feedforward synaptic transmission (PSC $\tau_{\text {fast }}$ ) were significant for both comparisons ( $t$ tests, paired comparisons; $p<0.0001$ ). $C$, The latencies for HC-to-cone feedback in individual cell pairs were calculated by subtracting time constants for feedforward synaptic release $\left(\tau_{\text {fast }}\right)$ from fast feedback time constants obtained at onset $\left(\tau_{\text {on }}\right)$ or offset ( $\tau_{\text {off }}$ ) of the hyperpolarizing test step $(-30$ to $-90 \mathrm{mV}$ ) applied to the HC. Latencies for feedback at onset of this test step averaged $13.5 \pm 1.8(\mathrm{~N}=24)$ and $10.6 \pm 1.6$ $\mathrm{ms}(N=18)$ for -30 and $-20 \mathrm{mV}$ trials, respectively (Fig. 3C). Latencies for feedback at offset were $11.3 \pm 1.5$ and $11.6 \pm 1.7 \mathrm{~ms}$ for -30 and $-20 \mathrm{mV}$ trials, respectively. These values were all significantly greater than zero (one sample $t$ test, $p<0.0001$ ). 
clamped pairs of cells using the same approaches. As illustrated in Figure $6 A$, application of hyperpolarizing steps from -30 to $-90 \mathrm{mV}$ in HCs evoked inward feedback currents in rods that were simultaneously voltage-clamped at $-30 \mathrm{mV}$. As in cones, feedback currents typically increased with a biexponential time course attaining an average amplitude of $-6.9 \pm$ $0.85 \mathrm{pA}(N=9)$. In the example shown in Figure $6 B$, the initial inward feedback current evoked in the rod by a hyperpolarizing $\mathrm{HC}$ step was fit with a single exponential of $11 \mathrm{~ms}$. The decline in feedback current at offset was fit with time constant of $9.5 \mathrm{~ms}$ (Fig. 6C). The fast time constants at onset and offset averaged $\tau_{\text {on }}=15.0 \pm 2.5$ and $\tau_{\text {off }}=11.1 \pm 1.0 \mathrm{~ms}$, respectively $(N=9$ pairs; Fig. $7 A)$, and did not differ significantly from one another ( $p=0.15$, paired $t$ test). The second time constant from double exponential fits to the inward feedback current averaged $165.0 \pm 36.6 \mathrm{~ms}$; the second time constant at offset of feedback averaged $93.0 \pm 33.2 \mathrm{~ms}$.

We also compared feedback currents and feedforward synaptic release in the same rod/HC pairs. Figure $6 D$ shows the PSC evoked in the same rod/HC pair by a depolarizing step from -70 to $-10 \mathrm{mV}$. This step evoked an initial fast PSC in the $\mathrm{HC}$ due to release of vesicles from the synaptic ribbon followed by a slower component of release reflecting nonribbon release triggered by CICR (Cadetti et al., 2006; Chen et al., 2014). In this $\mathrm{rod} / \mathrm{HC}$ pair, the fast release rate measured from the initial increase in PSC charge transfer yielded a time constant of $7.1 \mathrm{~ms}$ (Fig. $6 E$ ), faster than the fast feedback time constants of $11\left(\tau_{\text {on }}\right)$ and $9.5\left(\tau_{\text {off }}\right)$ ms measured at the same synapses (Fig. $6 B, C$ ). Overall, the fast time constant for feedforward release at $\mathrm{rod} / \mathrm{HC}$ synapses averaged $6.9 \pm 0.8 \mathrm{~ms}(N=8$; Fig. $7 A)$, faster than the average feedback time constants of $15.0\left(\tau_{\text {on }}\right)$ and $11.1\left(\tau_{\text {off }}\right)$ ms.

We assessed the limits on measurement kinetics in these $\mathrm{rod} / \mathrm{HC}$ pairs. Voltage-clamp time constants in this sample of rods $\left(\tau_{\text {rod }}\right)$ averaged $0.96 \pm 0.10 \mathrm{~ms}(N=9)$. The second voltageclamp time constant in $\mathrm{HCs}\left(\tau_{\mathrm{HC}}\right)$ averaged $2.55 \pm 0.36 \mathrm{~ms}$. As in cones, we measured $\mathrm{I}_{\mathrm{Ca}}$ kinetics in rods by voltage-clamping rods at $-30 \mathrm{mV}$ and applying a $5 \mathrm{mV}$ step for $25 \mathrm{~ms}$. We included 2 $\mathrm{mm} \mathrm{CsCl}$ in the bathing solution to block $\mathrm{I}_{\mathrm{h}}$ currents. We repeated the test step 30-60 times and averaged the resulting currents. We then subtracted passive capacitative and resistive currents averaged from repeated application (100 trials) of a 5 $\mathrm{mV}$ test step from $-70 \mathrm{mV}$. After subtracting the passive currents, we observed an inward $\mathrm{I}_{\mathrm{Ca}}$ averaging $15.4 \pm 2.1 \mathrm{pA}(N=5)$ that activated at onset of the depolarizing step with a time constant of $2.22 \pm 0.41 \mathrm{~ms}$ and deactivated at step offset with a time constant of $1.70 \pm 0.23 \mathrm{~ms}(N=5)$. For each cell, we then subtracted the rod voltage-clamp time constant from the channel activation and deactivation time constants to find that channel

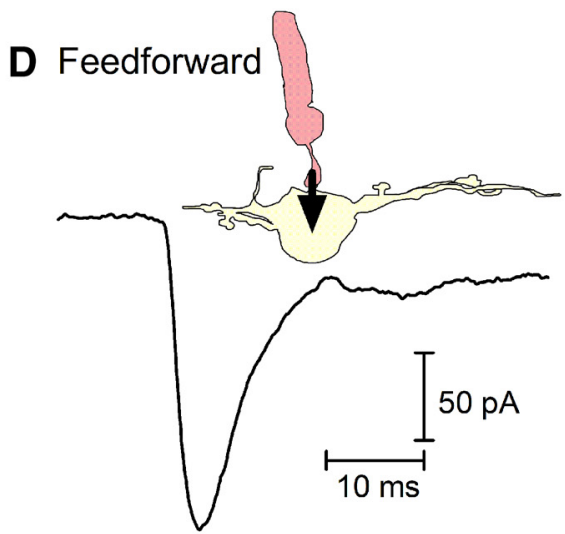

E
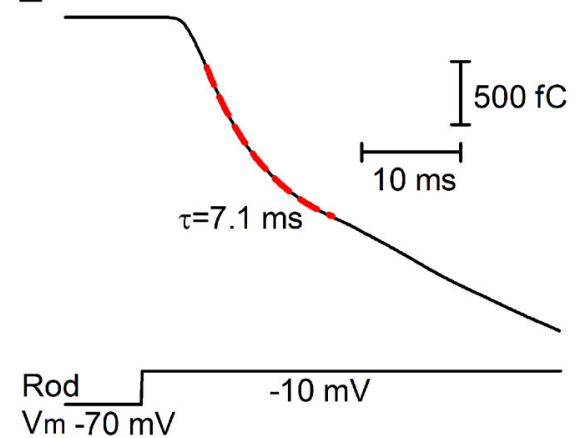

Figure 6. Comparing kinetics of inhibitory feedback to feedforward synaptic transmission at synapses between a rod and HC. $\boldsymbol{A}$, vol voltage step and decline in feedback current at offset. $\boldsymbol{B}$, Magnified view of the inward feedback current in the cone showing a

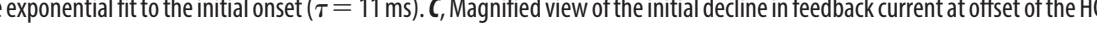
transfer of the PSC fit with a single exponential curve to the initial fast rise (amplitude $=1410 \mathrm{fC}, \tau_{1}=7.1 \mathrm{~ms}$ ). Protocol for the rod voltage change used to evoke a PSC in the HC is shown beneath $\boldsymbol{E}$.

activation kinetics added $1.31 \pm 0.25 \mathrm{~ms}\left(\tau_{\text {activ }}\right)$, whereas deactivation added $0.79 \pm 0.05 \mathrm{~ms}\left(\tau_{\text {deactiv }}, N=5\right)$.

We summed these values to calculate the limits on measurement of feedback kinetics. Subtracting measurement kinetics $\left(\tau_{\mathrm{HC}}+\tau_{\text {rod }}+\tau_{\text {activ }}\right.$ or $\left.\tau_{\mathrm{HC}}+\tau_{\text {rod }}+\tau_{\text {deactiv }}\right)$ from feedback time constants at onset $\left(\tau_{\text {on }}\right)$ or offset $\left(\tau_{\text {off }}\right)$ of the HC test step (Fig. $7 B$ ) yielded HC-to-rod feedback latencies averaging $10.1 \pm 2.5 \mathrm{~ms}$ at onset and $8.2 \pm 3.3 \mathrm{~ms}$ at offset $(N=9)$. Median values were 7.6 and $5.0 \mathrm{~ms}$, respectively. These latencies were significantly longer than the latencies of $0 \mathrm{~ms}$ predicted for an ephaptic mechanism (paired $t$ tests; $\tau_{\text {on }}, p=0.0037 ; \tau_{\text {off }}, p=0.0003$ ).

We also calculated feedback latency by subtracting time constants for feedforward release kinetics (PSC $\tau_{\text {fast }}$ ) from feedback time constants ( $\tau_{\text {on }}$ and $\tau_{\text {off }}$ ) measured at the same synapses in the same rod/HC pairs. Feedforward synaptic release at rod synapses averaged $3.4 \mathrm{~ms}$ slower than the summed voltage-clamp speed for HCs and rods suggesting a relatively long synaptic delay at rod synapses, consistent with slower release kinetics in rods than cones (Rabl et al., 2005; Van Hook and Thoreson, 2015). Even with this rather lengthy feedforward synaptic delay of $3.4 \mathrm{~ms}$, feedback was nevertheless significantly slower than feedforward 

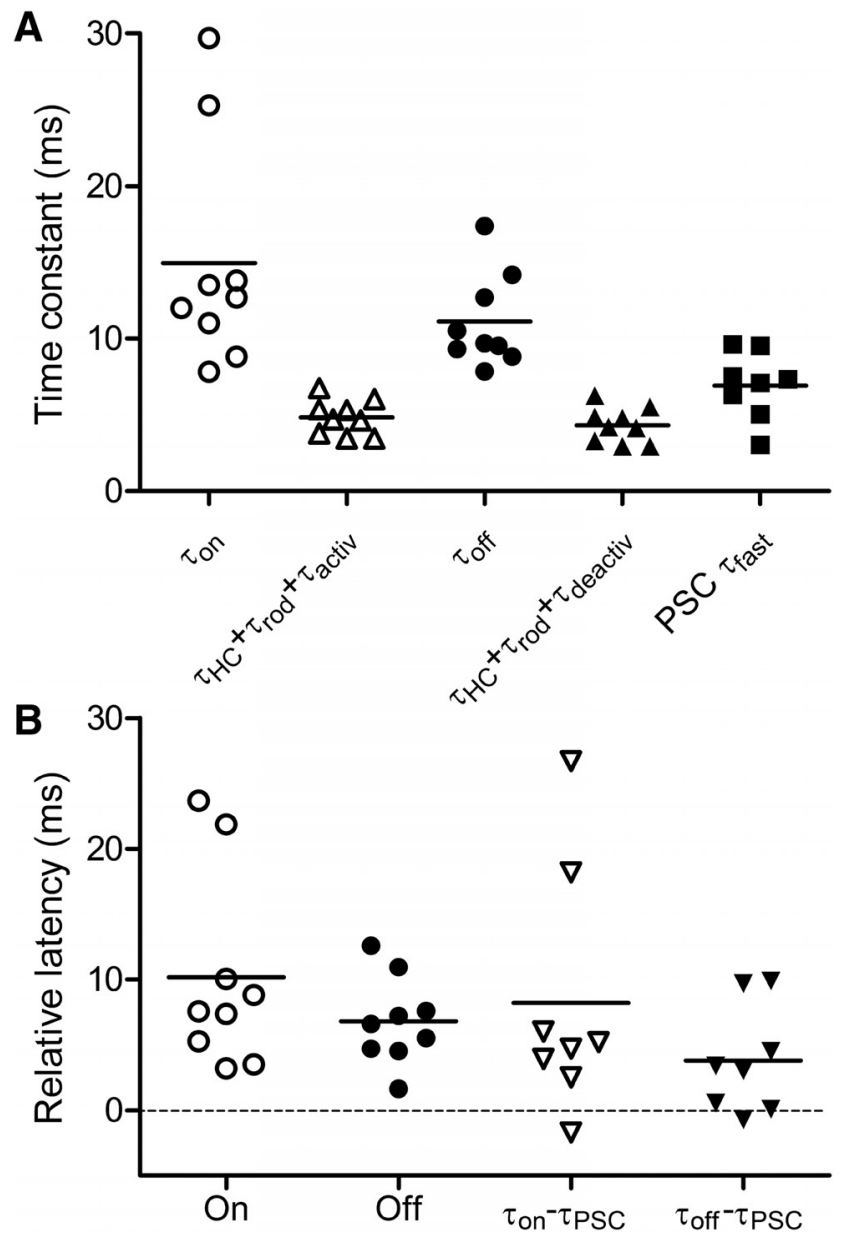

Figure 7. Comparisons of feedback, feedforward, and measurement kinetics at rod/HC synapses. $\boldsymbol{A}$, Scatter plot comparing fast feedback time constants measured in rods at onset $\left(\tau_{\text {on }}\right)$ or offset of the HC voltage step ( $\left.\tau_{\text {off }}\right)$, measurement kinetics (the sum of voltage-clamp time constants in the $\mathrm{HCs}$, voltage-clamp time constants in the rods, plus activation or deactivation kinetics of $\mathrm{Ca}^{2+}$ channels: $\tau_{\mathrm{HC}}+\tau_{\text {rod }}+\tau_{\text {activ }}$ and $\tau_{\mathrm{HC}}+\tau_{\text {rod }}+\tau_{\text {deactiv }}$ ), and feedforward release kinetics at the same synapses (time constants fit to the initial fast rise in PSC charge transfer: PSC $\left.\tau_{\text {fast }}\right)$. The differences between feedback time constants $\left(\tau_{\text {on }}\right.$ or $\left.\tau_{\text {off }}\right)$ and the corresponding measurement kinetics $\left(\tau_{\mathrm{HC}}+\tau_{\text {rod }}+\tau_{\text {activ }}\right.$ and $\left.\tau_{\mathrm{HC}}+\tau_{\text {rod }}+\tau_{\text {deactiv }}\right)$ were both significant (paired $t$ tests; $\tau_{\text {on' }} p=0.0037 ; \tau_{\text {off }} p=0.0003 ; N=9$ ). The differences between feedback time constants ( $\tau_{\text {on }}$ or $\tau_{\text {off }}$ ) and feedforward (PSC $\tau_{\text {fast }}$ ) transmission in the same pairs were also significant (paired tests; $\tau_{\text {on }}$ Vs $\tau_{\text {PSC, }} p=0.0430 ; \tau_{\text {off }}$ Vs $\tau_{\text {PSC }} p=0.0341$; $N=8)$. $\boldsymbol{B}$, Latencies for HC-to-rod feedback were calculated in individual cell pairs by subtracting measurement kinetics $\left(\tau_{\mathrm{HC}}+\tau_{\text {rod }}+\tau_{\text {activ }}\right.$ and $\left.\tau_{\mathrm{HC}}+\tau_{\text {rod }}+\tau_{\text {deactiv }}\right)$ from the corresponding fast feedback time constants at onset $(0 \mathrm{n})$ and offset $(\mathrm{Off})$ of the hyperpolarizing $\mathrm{HC}$ voltage step. Latencies were also calculated by subtracting time constants for feedforward synaptic transmission from feedback time constants at onset $\left(\tau_{\text {on }}-\tau_{\text {PSC }}\right)$ and offset $\left(\tau_{\text {off }}{ }^{-} \tau_{\text {PSC }}\right)$ of the HC step.

release with latencies of $8.2 \pm 3.3 \mathrm{~ms}$ at onset and $3.8 \pm 1.5 \mathrm{~ms}$ at offset $(N=8 ; p=0.043$ at onset, $p=0.034$ at offset; Fig. $7 B)$. These comparisons indicate that, like cones, HC feedback in rods shows slower kinetics than expected for an ephaptic mechanism involving continuously open channels.

\section{Discussion}

It has been hypothesized that at the invaginating cone-HC synapse current flowing through the synaptic cleft into open channels in HC dendrites can generate extracellular voltage changes (Byzov and Shura-Bura, 1986; Verweij et al., 1996). Extracellular voltage changes within the synaptic invagination can be converted into detectable cellular responses by altering the activity of adjacent $\mathrm{Ca}^{2+}$ channels in photoreceptor terminals (Vroman et al., 2013). While such ephaptic voltage changes should occur with no delay, time is required for $\mathrm{Ca}^{2+}$ channels to respond to a voltage change, and additional time is required for changes in $\mathrm{I}_{\mathrm{Ca}}$ to be detected by a voltage-clamp amplifier. To measure kinetics of inhibitory feedback from HCs to rods and cones, we applied hyperpolarizing steps to voltage-clamped HCs while simultaneously measuring feedback-induced changes in $\mathrm{I}_{\mathrm{Ca}}$ in synaptically connected photoreceptors. The rate at which the HC membrane potential changes is limited by HC voltage-clamp speed. We therefore compared the latency of feedback currents in photoreceptors to limits imposed by $\mathrm{Ca}^{2+}$ channel kinetics and the combined voltage-clamp latencies in the two cells. Both comparisons showed median latencies of 7-10 ms for HC-to-cone feedback and 5-8 ms for HC-to-rod feedback, much slower than predicted for an ephaptically-mediated voltage change.

Recordings of voltage changes in cones evoked by annular illumination of the receptive field surround revealed multiple components of HC-to-cone feedback (Fuortes et al., 1973; O'Bryan, 1973) involving both sustained voltage changes and regenerative responses arising from activation of cone $\mathrm{I}_{\mathrm{Ca}}$ (Piccolino and Gerschenfeld, 1978, 1980; Burkhardt et al., 1988). Like Vroman et al. (2014), we saw both fast and slow components to feedback currents, even in cones that were voltage-clamped to prevent regenerative activation of $\mathrm{I}_{\mathrm{Ca}}$. Fast feedback allows spatially averaged luminance to be constantly subtracted from local changes, even during rapidly changing visual scenes (Vroman et al., 2013, 2014). While we found that fast feedback is not instantaneous, it is still sufficiently fast to serve this purpose. Light responses of HCs show rise times of tens of milliseconds (Yamada et al., 1985; Yang and $\mathrm{Wu}, 1989$ ), shaped largely by the kinetics of photoreceptor light responses (Baylor and Hodgkin, 1973). Glutamate release and binding are sufficiently fast to not appreciably influence HC light response kinetics (Witkovsky et al., 2001). The slow kinetics of $\mathrm{HC}$ light responses limits the temporal resolution of comparisons with cone feedback kinetics, and this might explain why HC light responses and surround-evoked feedback responses of fish cones showed nearly identical kinetics (Kamermans et al., 2001b; Vroman et al., 2013, 2014). Feedback mechanisms may also differ among species. Zebrafish lacking connexin 55.5 hemichannels showed smaller surround-evoked changes in cone $\mathrm{I}_{\mathrm{Ca}}$ (Klaassen et al., 2011; Vroman et al., 2014), whereas eliminating connexins 50 or 57 from mouse HCs did not appear to diminish feedback (Shelley et al., 2006; Dorgau et al., 2015).

The inward feedback currents observed in this study at holding potentials of -20 or $-30 \mathrm{mV}$ reflect the increase in photoreceptor $\mathrm{I}_{\mathrm{Ca}}$ that is caused by a negative shift in $\mathrm{I}_{\mathrm{Ca}}$ activation voltage and overall increase in $\mathrm{I}_{\mathrm{Ca}}$ amplitude (Verweij et al., 1996; Hirasawa and Kaneko, 2003). Inward feedback currents in cones were inhibited by application of HEPES, suggesting that both fast and slow components involve $\mathrm{pH}$ changes. The fast component of feedback likely represents direct feedback effects on $\mathrm{I}_{\mathrm{Ca}}$. The second component may reflect slow changes in cleft proton levels that could in turn drive slow changes in $\mathrm{I}_{\mathrm{Ca}}$. Additionally, by elevating cytoplasmic $\mathrm{Ca}^{2+}$, feedback-induced increases in $\mathrm{I}_{\mathrm{Ca}}$ should activate $\mathrm{Ca}^{2+}$-dependent $\mathrm{Cl}^{-}$and $\mathrm{K}^{+}$channels that could shape slow feedback currents, although these currents should be outward under the conditions of our experiments.

The speed with which we detected changes in feedback currents in photoreceptors was limited by voltage-clamp speed. Capacitative transients in cones declined with an exponential time course exhibiting a time constant of $\sim 2 \mathrm{~ms}$; rods showed a voltage-clamp time constant of $\sim 1 \mathrm{~ms}$. Much of the time needed 
for charging cone membrane capacitance is needed for charging the large outer segment membrane. Synaptic terminals of salamander cones are located at the base of the cell body, placing them electrotonically closer to a recording pipette on the inner segment than outer segments connected to inner segments through a thin cilium. Thus, the cone membrane time constant of 2 ms likely represents an upper limit to the speed at which cone $\mathrm{Ca}^{2+}$ channels can be voltage-clamped.

To measure the speed with which an applied voltage change is attained by an $\mathrm{HC}$, we used a current-clamp pipette to record the voltage change produced by a voltage step applied through a second voltage-clamp pipette. The capacitative current transient declined in voltage-clamped HCs with a time course best described by a sum of two exponentials, consistent with charging of two electrotonic compartments. The dominant time constant for the accompanying change in membrane voltage measured by current clamp closely matched the second exponential of the capacitative current. Our modeling of $\mathrm{HC}$ dendrites indicated that HC dendrites should also be rapidly voltage-clamped. The ability to record rapid feedforward PSCs at the same synapses confirmed that $\mathrm{HC}$ dendrites mediating feedback in these paired recordings were not electrotonically distant. Summing the voltage-clamp time constants in cone/HC pairs yielded a value that was only $\sim 0.5 \mathrm{~ms}$ faster than the fast time constant measured for feedforward synaptic transmission, indicating that the summed cone and $\mathrm{HC}$ time constants provide a good estimate of the actual voltage-clamp speed at cone/HC synapses. At rod synapses, the time constant for feedforward synaptic release was $\sim 3.5$ ms slower than summed rod and $\mathrm{HC}$ voltage-clamp speeds. The longer delay at rod synapses may reflect their slower release kinetics (Rabl et al., 2005; Van Hook and Thoreson, 2015), but rod synapses, unlike cone synapses, are located at the end of a thin axon and may be more electrotonically distant. Nevertheless, even these slow synaptic responses were significantly faster than feedback kinetics measured at the same rod/HC synapses.

In addition to the voltage-clamp speed of photoreceptors and $\mathrm{HCs}$, a certain amount of time is required for L-type $\mathrm{Ca}^{2+}$ channels in rod or cone terminals to respond to a change in voltage within the synaptic cleft. Stimulating cones with a step from -30 to $-25 \mathrm{mV}$ activated $\mathrm{I}_{\mathrm{Ca}}$ with a time constant of $3.1 \mathrm{~ms}$. At offset of the step, $\mathrm{I}_{\mathrm{Ca}}$ deactivated with a time constant of $4.2 \mathrm{~ms}$. These time constants incorporate both voltage-clamp speed and channel kinetics. We therefore subtracted the membrane time constants to determine that channel activation kinetics $\left(\tau_{\text {activ }}\right)$ added an additional $0.83 \mathrm{~ms}$ in cones, whereas deactivation $\left(\tau_{\text {deactiv }}\right)$ added another $1.96 \mathrm{~ms}$ in cones. In rods, channel activation kinetics added $0.79 \mathrm{~ms}$ and deactivation added $1.3 \mathrm{~ms}$.

By comparing feedback current kinetics with the sum of HC voltage-clamp speed, photoreceptor voltage-clamp speed, and $\mathrm{I}_{\mathrm{Ca}}$ kinetics, we found that feedback at rod and cone synapses showed a much longer delay than expected for an ephaptic mechanism. Furthermore, the speed of feedback from HCs to cones was much slower than feedforward synaptic transmission from cones to HCs measured across the same synapses. Each cone contacts an individual $\mathrm{HC}$ at a handful of ribbon synapses, and both feedback and feedforward interactions occur at these same few synapses. Because an ephaptic mechanism should be faster than a chemical mechanism, the finding that feedforward kinetics of release was substantially faster than feedback kinetics provides compelling evidence that feedback regulation of $\mathrm{I}_{\mathrm{Ca}}$ is not mediated by an ephaptic mechanism. Even at slow rod synapses, feedback kinetics was slower than feedforward release kinetics. It is possible that there were contributions from tiny ephaptic voltage changes that were obscured by baseline noise, but we minimized this possibility by averaging 3-10 trials in each experiment.

Our results eliminate the possibility of significant ephaptic changes mediated by continuously open channels (e.g., hemigap junctions). However, we cannot eliminate the possibility that slowly varying conductances (e.g., $\mathrm{K}^{+}$channels) in the $\mathrm{HC}$ membrane might have slow ephaptic effects. We held cones at a constant voltage for 2-3 s before testing feedback to allow glutamate release from cones to attain a steady state. We did not observe ephaptic effects under these conditions, but it is possible that a large burst of glutamate release evoked by strong cone depolarization might produce more significant effects.

Our results are consistent with previous evidence that the major mechanism mediating inhibitory feedback effects of $\mathrm{HCs}$ on cone $\mathrm{I}_{\mathrm{Ca}}$ involves changes in synaptic cleft $\mathrm{pH}$ ( Hirasawa and Kaneko, 2003; Vessey et al., 2005; Wang et al., 2014). HC-to-rod feedback also involves pH-dependent mechanisms (Thoreson et al., 2008; Babai and Thoreson, 2009). Exactly how changes in HC membrane potential produce changes in cleft $\mathrm{pH}$ during feedback remains unclear (Kramer and Davenport, 2015). The finding that the kinetics of negative feedback from HCs to photoreceptors is considerably slower than feedforward glutamate release at the same synapses suggests that this $\mathrm{pH}$-dependent mechanism is unlikely to use conventional mechanisms of synaptic transmission.

\section{References}

Anastassiou CA, Koch C (2015) Ephaptic coupling to endogenous electric field activity: why bother? Curr Opin Neurobiol 31:95-103. CrossRef Medline

Arvanitaki A (1942) Effects evoked in an axon by the activity of a contiguous one. J Neurophysiol 5:89-108.

Babai N, Thoreson WB (2009) Horizontal cell feedback regulates calcium currents and intracellular calcium levels in rod photoreceptors of salamander and mouse retina. J Physiol 587:2353-2364. CrossRef Medline

Bartoletti TM, Babai N, Thoreson WB (2010) Vesicle pool size at the salamander cone ribbon synapse. J Neurophysiol 103:419-423. CrossRef Medline

Baumann L, Gerstner A, Zong X, Biel M, Wahl-Schott C (2004) Functional characterization of the L-type $\mathrm{Ca}^{2+}$ channel Cav1.4alphal from mouse retina. Invest Ophthalmol Vis Sci 45:708-713. CrossRef Medline

Baylor DA, Hodgkin AL (1973) Detection and resolution of visual stimuli by turtle photoreceptors. J Physiol 234:163-198. CrossRef Medline

Baylor DA, Fuortes MG, O’Bryan PM (1971) Lateral interaction between vertebrate photoreceptors. Vision Res 11:1195-1196. CrossRef Medline

Blot A, Barbour B (2014) Ultra-rapid axon-axon ephaptic inhibition of cerebellar Purkinje cells by the pinceau. Nat Neurosci 17:289-295. CrossRef Medline

Burkhardt DA, Gottesman J, Thoreson WB (1988) Prolonged depolarization in turtle cones evoked by current injection and stimulation of the receptive field surround. J Physiol 407:329-348. CrossRef Medline

Byzov AL, Shura-Bura TM (1986) Electrical feedback mechanism in the processing of signals in the outer plexiform layer of the retina. Vision Res 26:33-44. CrossRef Medline

Cadenas ID, Reifsnider ES, Tranchina D (1994) Modulation of synaptic transfer between retinal cones and horizontal cells by spatial contrast. J Gen Physiol 104:567-591. CrossRef Medline

Cadetti L, Thoreson WB (2006) Feedback effects of horizontal cell membrane potential on cone calcium currents studied with simultaneous recordings. J Neurophysiol 95:1992-1995. CrossRef Medline

Cadetti L, Tranchina D, Thoreson WB (2005) A comparison of release kinetics and glutamate receptor properties in shaping rod-cone differences in EPSC kinetics in the salamander retina. J Physiol 569:773-788. CrossRef Medline

Cadetti L, Bryson EJ, Ciccone CA, Rabl K, Thoreson WB (2006) Calciuminduced calcium release in rod photoreceptor terminals boosts synaptic 
transmission during maintained depolarization. Eur J Neurosci 23: 2983-2990. CrossRef Medline

Cadetti L, Bartoletti TM, Thoreson WB (2008) Quantal mEPSCs and residual glutamate: how horizontal cell responses are shaped at the photoreceptor ribbon synapse. Eur J Neurosci 27:2575-2586. CrossRef Medline

Cavalié A, McDonald TF, Pelzer D, Trautwein W (1985) Temperatureinduced transitory and steady-state changes in the calcium current of guinea pig ventricular myocytes. Pflugers Arch 405:294-296. CrossRef Medline

Chen M, Križaj D, Thoreson WB (2014) Intracellular calcium stores drive slow non-ribbon vesicle release from rod photoreceptors. Front Cell Neurosci 8:20. CrossRef Medline

Corey DP, Dubinsky JM, Schwartz EA (1984) The calcium current in inner segments of rods from the salamander (Ambystoma tigrinum) retina. J Physiol 354:557-575. CrossRef Medline

Cota G, Nicola Siri L, Stefani E (1983) Calcium-channel gating in frog skeletal muscle membrane: effect of temperature. J Physiol 338:395412. CrossRef Medline

Curtis DR, Johnston GA (1974) Amino acid transmitters in the mammalian central nervous system. Ergeb Physiol 69:97-188. Medline

Dorgau B, Herrling R, Schultz K, Greb H, Segelken J, Ströh S, Bolte P, Weiler R, Dedek K, Janssen-Bienhold U (2015) Connexin50 couples axon terminals of mouse horizontal cells by homotypic gap junctions. J Comp Neurol 523:2062-2081. CrossRef Medline

Fry CH, Salvage SC, Manazza A, Dupont E, Labeed FH, Hughes MP, Jabr RI (2012) Cytoplasm resistivity of mammalian atrial myocardium determined by dielectrophoresis and impedance methods. Biophys J 103: 2287-2294. CrossRef Medline

Fuortes MG, Schwartz EA, Simon EJ (1973) Colour-dependence of cone responses in the turtle retina. J Physiol 234:199-216. CrossRef Medline

Hartline HK, Wagner HG, Ratliff F (1956) Inhibition in the eye of Limulus. J Gen Physiol 39:651-673. CrossRef Medline

Hirano AA, Liu X, Boulter J, Grove J, Pérez de Sevilla Müller L, Barnes S, Brecha NC (2016) Targeted deletion of vesicular GABA transporter from retinal horizontal cells eliminates feedback modulation of photoreceptor calcium channels. eNeuro 3:piiENEURO.0148-15-2016. CrossRef Medline

Hirasawa H, Kaneko A (2003) pH changes in the invaginating synaptic cleft mediate feedback from horizontal cells to cone photoreceptors by modulating $\mathrm{Ca}^{2+}$ channels. J Gen Physiol 122:657-671. CrossRef Medline

Kamermans M, Fahrenfort I, Schultz K, Janssen-Bienhold U, Sjoerdsma T, Weiler R (2001a) Hemichannel-mediated inhibition in the outer retina. Science 292:1178-1180. CrossRef Medline

Kamermans M, Kraaij D, Spekreijse H (2001b) The dynamic characteristics of the feedback signal from horizontal cells to cones in the goldfish retina. J Physiol 534:489-500. CrossRef Medline

Kemmler R, Schultz K, Dedek K, Euler T, Schubert T (2014) Differential regulation of cone calcium signals by different horizontal cell feedback mechanisms in the mouse retina. J Neurosci 34:11826-11843. CrossRef Medline

Klaassen LJ, Sun Z, Steijaert MN, Bolte P, Fahrenfort I, Sjoerdsma T, Klooster J, Claassen Y, Shields CR, Ten Eikelder HM, Janssen-Bienhold U, Zoidl G, McMahon DG, Kamermans M (2011) Synaptic transmission from horizontal cells to cones is impaired by loss of connexin hemichannels. PLoS Biol 9:e1001107. CrossRef Medline

Kramer RH, Davenport CM (2015) Lateral inhibition in the vertebrate retina: the case of the missing neurotransmitter. PLoS Biol 13:e1002322. CrossRef Medline

Lam DM, Lasater EM, Naka KI (1978) gamma-Aminobutyric acid: a neurotransmitter candidate for cone horizontal cells of the catfish retina. Proc Natl Acad Sci U S A 75:6310-6313. CrossRef Medline

Lasansky A (1973) Organization of the outer synaptic layer in the retina of the larval tiger salamander. Philos Trans R Soc Lond B Biol Sci 265: 471-489. CrossRef Medline

Liu X, Hirano AA, Sun X, Brecha NC, Barnes S (2013) Calcium channels in rat horizontal cells regulate feedback inhibition of photoreceptors through an unconventional GABA- and pH-sensitive mechanism. J Physiol 591:3309-3324. CrossRef Medline

Mansergh F, Orton NC, Vessey JP, Lalonde MR, Stell WK, Tremblay F, Barnes S, Rancourt DE, Bech-Hansen NT (2005) Mutation of the calcium channel gene Cacnalf disrupts calcium signaling, synaptic transmission and cellular organization in mouse retina. Hum Mol Genet 14:3035-3046. CrossRef Medline

Morgans CW (2001) Localization of the alpha(1F) calcium channel subunit in the rat retina. Invest Ophthalmol Vis Sci 42:2414-2418. Medline

O'Bryan PM (1973) Properties of the depolarizing synaptic potential evoked by peripheral illumination in cones of the turtle retina. J Physiol 235:207-223. CrossRef Medline

Oltedal L, Veruki ML, Hartveit E (2009) Passive membrane properties and electrotonic signal processing in retinal rod bipolar cells. J Physiol 587: 829-849. CrossRef Medline

Pang JJ, Gao F, Barrow A, Jacoby RA, Wu SM (2008) How do tonic glutamatergic synapses evade receptor desensitization? J Physiol 586:28892902. CrossRef Medline

Pereda AE (2014) Electrical synapses and their functional interactions with chemical synapses. Nat Rev Neurosci 15:250-263. CrossRef Medline

Piccolino M, Gerschenfeld HM (1978) Activation of a regenerative calcium conductance in turtle cones by peripheral stimulation. Proc R Soc Lond B Biol Sci 201:309-315. CrossRef Medline

Piccolino M, Gerschenfeld HM (1980) Characteristics and ionic processes involved in feedback spikes of turtle cones. Proc R Soc Lond B Biol Sci 206:439-463. CrossRef Medline

Pilwat G, Zimmermann U (1985) Determination of intracellular conductivity from electrical breakdown measurements. Biochim Biophys Acta 820: 305-314. CrossRef Medline

Qian H, Pan Y, Zhu Y, Khalili P (2005) Picrotoxin accelerates relaxation of $\mathrm{GABA}_{\mathrm{C}}$ receptors. Mol Pharmacol 67:470-479. CrossRef Medline

Rabl K, Cadetti L, Thoreson WB (2005) Kinetics of exocytosis is faster in cones than in rods. J Neurosci 25:4633-4640. CrossRef Medline

Rabl K, Cadetti L, Thoreson WB (2006) Paired-pulse depression at photoreceptor synapses. J Neurosci 26:2555-2563. CrossRef Medline

Reifsnider ES, Tranchina D (1995) Background spatial contrast modulates kinetics and lateral spread of responses to superimposed stimuli in the outer retina. Vis Neurosci 12:1105-1126. CrossRef Medline

Shelley J, Dedek K, Schubert T, Feigenspan A, Schultz K, Hombach S, Willecke K, Weiler R (2006) Horizontal cell receptive fields are reduced in connexin57-deficient mice. Eur J Neurosci 23:3176-3186. CrossRef Medline

Shelton DP (1985) Membrane resistivity estimated for the Purkinje neuron by means of a passive computer model. Neuroscience 14:111-131. CrossRef Medline

Tatsukawa T, Hirasawa H, Kaneko A, Kaneda M (2005) GABA-mediated component in the feedback response of turtle retinal cones. Vis Neurosci 22:317-324. CrossRef Medline

Thoreson WB, Burkhardt DA (1990) Effects of synaptic blocking agents on the depolarizing responses of turtle cones evoked by surround illumination. Vis Neurosci 5:571-583. CrossRef Medline

Thoreson WB, Mangel SC (2012) Lateral interactions in the outer retina. Prog Retin Eye Res 31:407-441. CrossRef Medline

Thoreson WB, Babai N, Bartoletti TM (2008) Feedback from horizontal cells to rod photoreceptors in vertebrate retina. J Neurosci 28:5691-5695. CrossRef Medline

Thoreson WB, Van Hook MJ, Parmelee C, Curto C (2016) Modeling and measurement of vesicle pools at the cone ribbon synapse: changes in release probability are solely responsible for voltage-dependent changes in release. Synapse 70:1-14.

Van Hook MJ, Thoreson WB (2013) Simultaneous whole-cell recordings from photoreceptors and second-order neurons in an amphibian retinal slice preparation. J Vis Exp 76:e50007. CrossRef Medline

Van Hook MJ, Thoreson WB (2015) Weak endogenous $\mathrm{Ca}^{2+}$ buffering supports sustained synaptic transmission by distinct mechanisms in rod and cone photoreceptors in salamander retina. Physiol Rep 3:e12567. CrossRef Medline

VanLeeuwen M, Fahrenfort I, Sjoerdsma T, Numan R, Kamermans M (2009) Lateral gain control in the outer retina leads to potentiation of center responses of retinal neurons. J Neurosci 29:6358-6366. CrossRef Medline

Verweij J, Kamermans M, Spekreijse H (1996) Horizontal cells feed back to cones by shifting the cone calcium-current activation range. Vision Res 36:3943-3953. CrossRef Medline

Verweij J, Hornstein EP, Schnapf JL (2003) Surround antagonism in macaque cone photoreceptors. J Neurosci 23:10249-10257. Medline 
Vessey JP, Stratis AK, Daniels BA, Da Silva N, Jonz MG, Lalonde MR, Baldridge WH, Barnes S (2005) Proton-mediated feedback inhibition of presynaptic calcium channels at the cone photoreceptor synapse. J Neurosci 25:4108-4117. CrossRef Medline

Vroman R, Klaassen LJ, Kamermans M (2013) Ephaptic communication in the vertebrate retina. Front Hum Neurosci 7:612. CrossRef Medline

Vroman R, Klaassen LJ, Howlett MH, Cenedese V, Klooster J, Sjoerdsma T, Kamermans M (2014) Extracellular ATP hydrolysis inhibits synaptic transmission by increasing $\mathrm{pH}$ buffering in the synaptic cleft. PLoS Biol 12:e1001864. CrossRef Medline

Wang DS, Buckinx R, Lecorronc H, Mangin JM, Rigo JM, Legendre P (2007) Mechanisms for picrotoxinin and picrotin blocks of alpha2 homomeric glycine receptors. J Biol Chem 282:16016-16035. CrossRef Medline

Wang TM, Holzhausen LC, Kramer RH (2014) Imaging an optogenetic pH sensor reveals that protons mediate lateral inhibition in the retina. Nat Neurosci 17:262-268. CrossRef Medline
Warren TJ, Van Hook MJ, Supuran CT, Thoreson WB (2016) Sources of protons and a role for bicarbonate in inhibitory feedback from horizontal cells to cones in Ambystoma tigrinum retina. J Physiol. Advance online publication. Retrieved Jun. 27, 2016. doi: 10.1113/JP272533. CrossRef Medline

Witkovsky P, Thoreson W, Tranchina D (2001) Transmission at the photoreceptor synapse. Prog Brain Res 131:145-159. CrossRef Medline

Wu SM (1991) Input-output relations of the feedback synapse between horizontal cells and cones in the tiger salamander retina. J Neurophysiol 65:1197-1206. Medline

Yamada M, Shigematsu Y, Fuwa M (1985) Latency of horizontal cell response in the carp retina. Vision Res 25:767-774. CrossRef Medline

Yang XL, Wu SM (1989) Effects of background illumination on the horizontal cell responses in the tiger salamander retina. J Neurosci 9:815-827. Medline 